\title{
MODELLING THE KEY ENABLERS OF ORGANIZATIONAL BUILDING INFORMATION MODELLING (BIM) IMPLEMENTATION: AN INTERPRETIVE STRUCTURAL MODELLING (ISM) APPROACH
}

\author{
SUBMITTED: August 2020 \\ REVISED: October 2021 \\ PUBLISHED: November 2021 \\ EDITOR: Esther Obonyo \\ DOI: $10.36680 /$ j.itcon.2021.052
}

Behzad Abbasnejad, Lecturer,

School of Property, Construction and Project Management, RMIT University, Melbourne, Australia; Behzad.abbasnejad@rmit.edu.au

Madhav Prasad Nepal, Senior Lecturer,

School of Architecture \& Built Environment, Queensland University of Technology, Brisbane, Australia; madhav.nepal@qut.edu.au

Seyed Armin Mirhosseini, Researcher, School of Civil Engineering, Iran University of Science \& Technology, Tehran, Iran; arminmirhoseiny@gmail.com

Hashem Izadi Moud, Assistant Professor, Construction Management Department, U.A Whitaker College of Engineering, Florida Gulf Coast University, USA; hizadimoud@fgcu.edu

\author{
Alireza Ahankoob, Lecturer, \\ School of Property, Construction and Project Management, RMIT University, Melbourne, Australia; \\ Alireza.ahankoob@rmit.edu.au
}

SUMMARY: Building Information Modelling (BIM) implementation is a dynamic process and there are a number of influential variables that may change throughout. There is little research on the dynamics of the change environment and the AEC organizations' approaches to BIM adoption and implementation. A considerable number of BIM enablers have been identified and/or developed in the extant literature. However, stipulating BIM implementation enablers per se provides only a static view that is not adequate for describing effective management of BIM implementation in Architectural, Engineering, and Construction (AEC) organizations. This study is the second part of an ongoing research about BIM implementation enablers. In the first paper "Building Information Modelling (BIM) adoption and implementation enablers in AEC firms: a systematic literature review" (Abbasnejad et al., 2020) the organizational BIM enablers have been identified. The aim of this second paper is to (1) further review and validate the key BIM implementation enablers using both the existing literature and expert interviews, and (2) develop a structural model of the key enablers using the ISM technique to understand the mutual interaction of these enablers and identify the driving enablers and the dependent enablers. Twentyeight enablers for BIM implementation were initially identified from the literature and subsequent discussion with experts from academia and industry has been conducted to select most key BIM implementation enablers. Eleven enablers were finally chosen based on the literature review and expert interviews and the Interpretive Structural Modeling (ISM) technique has been adopted to evaluate the contextual interrelationships among them. MICMAC (Matrix Impacts Cross-reference Multiplication Applied to a Classification) analysis was employed to classify the eleven enablers based on their dependence and driving power. The results indicate that there is no enabler in the autonomous cluster and this therefore signifies that all enablers are required for the implementation of BIM. BIM leadership and top management support have been identified as the enablers with the highest driving power in the initial stages of the BIM adoption and implementation process and for that reason, these enablers demand a greater priority given that there are other dependent enablers that will be impacted.

KEYWORDS: building information modelling, innovation implementation, ISM approach, business process change management, construction management

REFERENCE: Behzad Abbasnejad, Madhav Prasad Nepal, Seyed Armin Mirhosseini, Hashem Izadi Moud, Alireza Ahankoob (2021). Modelling the key enablers of organizational building information modelling (BIM) implementation: An interpretive structural modelling (ISM) approach. Journal of Information Technology in Construction (ITcon), Vol. 26, pg. 974-1008, DOI: 10.36680/j.itcon.2021.052

COPYRIGHT: (C) 2021 The author(s). This is an open access article distributed under the terms of the Creative Commons Attribution 4.0 International (https://creativecommons.org/licenses/by/4.0/), which permits unrestricted use, distribution, and reproduction in any medium, provided the original work is properly cited. 


\section{INTRODUCTION}

A number of innovative initiatives have been introduced and implemented over the past decade in the Architectural, Engineering and Construction (AEC) industry. Building information modeling (BIM) has been established as a prevalent initiative within the AEC industry. BIM is defined as "a set of interacting policies, processes and technologies that generate a methodology to manage the building design and project data in digital format throughout the building's life cycle" (Succar et al., 2012). Furthermore, BIM is considered as a "system" innovation (Murphy, 2014; Succar \& Kassem, 2015) due to it being a set of interacting policies, processes and technologies that work in tandem throughout a built facility. According to Slaughter (1998), "system innovations are identified through their integration of multiple independent innovations that must work together to perform new functions or improve the facility performance as a whole". In the BIM domain, complex systems, characterized by the integration of a changing set of components, must interact in order to both perform the overall function as well as meet the AEC firms' expectations over time. This large scale of integration makes BIM implementation a highly complex and interdependent process.

As a result, BIM presents significant challenges to the adopting organizations. It not only entails substantial human, technical, and managerial resources but also a redesign of business processes, structure, and patterns of work flow. Additionally, BIM implementation requires contribution of several employees and external entities such as the BIM manager, employees from various business units, and external vendors and consultants. It also includes multiple tasks such as BIM-authoring software selection, training and education. Due to its systemic and multifaceted nature, the output of BIM implementation combines several diverse features. These consist of multiple dimensions such as financial index (e.g. Return on Investment (ROI)), information sharing capabilities (e.g. quality of information) and operational metrics (e.g. reduction of design errors and reworks).

In order to achieve the improved benefits of BIM tools and workflows, the implementation of BIM should be meticulously executed by considering a multitude of influencing factors. For instance, when implementing BIM, AEC firms might face a number of barriers throughout such as resistance to change, lack of availability of resources, and complexity of BIM vendor selection. Due to the nature of these barriers, many AEC firms are reluctant to take up and apply BIM tools and concepts. In response, a number of enablers in the form of critical success factors, tools, techniques, and decision support systems have been identified and developed in the extant BIM literature. Necessarily, these enablers empower AEC firms to effectively and efficiently implement BIM tools and concepts. However, these enablers and their effectiveness require further analysis and their interrelationships furthermore entail a more comprehensive understanding to precipitate the optimization of benefits in the BIM implementation process.

Key BIM enablers not only affect the implementation process but also influence one another in significant ways (Ahmed and Kassem, 2018). Most of the extant BIM studies took a primarily static approach and explored the key BIM enablers per se. Even though these studies are critical for enhanced understanding and decision making in BIM implementation, they only provide a narrow view of enablers. Few studies have been conducted to model the key enablers of organizational BIM implementation. BIM implementation is a variable stage-based process, and its influential factors are constantly in a process of change. It is therefore critical to understand the nature of these enablers and their interrelationships in BIM implementation. To provide an enhanced understanding of this process, this research aims to model the structural relationships between the BIM implementation enablers. The Interpretive Structural Modelling (ISM) approach has been adopted in this paper to explore the interlocking and fluctuating relationships amongst BIM's key enablers to identify their driving power and dependencies. The main objectives of this research are as follows:

- To identify and discuss the significance of the key organizational BIM implementation enablers;

- To explore relationships amongst these enablers using the ISM technique;

- To rank the key BIM implementation enablers based on their driving power and dependencies and discuss the implications of these.

In what follows is initially a discussion of the key enablers of BIM implementation through a literature review and expert interviews. In the subsequent sections, an overview of the ISM technique is provided followed by its application in the modelling of key enablers of the BIM implementation process. Matrix Impacts Cross-reference Multiplication Applied to a Classification (MICMAC) analysis of these enablers is presented and the discussion and conclusions are drawn afterwards. 


\section{LITERATURE REVIEW 2.1 BIM IMPLEMENTATION}

BIM implementation is defined as " a set of activities undertaken by an organisational unit to prepare for, deploy or improve its BIM deliverables (products) and their related workflows (processes)" (Succar and Kassem, 2015). Accordingly, BIM implementation enablers refer to a set of tools, techniques and strategies to facilitate the BIM readiness, capability and maturity phases (Abbasnejad et al., 2018). To gauge a comprehensive evaluation of the key organizational BIM implementation enablers, different organizational levels such as individuals, groups (different organizational working divisions/functions), as well as the entire organization itself should be taken into account. At the individual level, key aspects comprise individual characteristics, individual competencies including their skills, abilities, and experiences as well as user learning and training. At the group level, key aspects comprise communication, coordination, collaboration and cross-functional/group training. At the organizational level, key aspects include organizational culture and structure, leadership, top management support, communication and collaboration (Peansupap \& Walker, 2005).

BIM tools and concepts may be mandated to an organization or initiated from individuals inside a particular organization and then employed on a small-scale basis in a given division/group within the organization as whole. BIM implementation entails advocates and can be subject to pilot testing in certain organizational functions/divisions before application within the organization (Ciribini et al., 2016). Moreover, for successful implementation and realization of BIM's maximum potentials, it has to be diffused and effectively implemented both internally within the organizational context and externally through collaborative networks of various parties (Papadonikolaki, 2018). According to the Theory of Innovation Diffusion (Rogers, 2003), an innovation diffuses throughout a given social system. Throughout the channels of communication, diffusion is a process of change amongst members of a social system to create mutual understanding and to aid the altering of the process over time. As BIM diffusion takes place across varied functions and within the entire organization, it entails additional task interdependence and the resulting institutional context imposes increased obstacles (Bosch-Sijtsema et al., 2017). However, these can be overcome through setting key BIM implementation enablers such as new coordination mechanisms, advanced digital tools, advanced monitoring and controlling systems (Keskin et al., 2019), and changes to organizational goals, objectives, and strategies.

\subsection{IDENTIFICATION OF BIM IMPLEMENTATION ENABLERS}

The enablers used in this paper were extracted from the study previously conducted by the first author (Abbasnejad, 2018; Abbasnejad et al., 2020) in which Succar's definition of BIM (Succar, 2009) and Business Process Change Management Constructs (Kettinger and Grover, 1995) were applied to identify the key organizational BIM enablers. Before modelling the key BIM implementation enablers, it is necessary to understand the significance of each enabler and the role each enabler plays in the overall BIM implementation process. Implementing BIM as an innovation in construction context aims to modify the current business processes of AEC organizations. Given the transformative adoption of BIM by AEC firms, BIM implementation should be considered as an organizational innovation (Succar \& Kassem, 2015). Organizational innovation is defined as "the adoption of an idea or behavior that is new to the organization" and is subject to influences in individual, organizational, and environmental components (Hage, 1999). In addition, it is widely discussed that BIM implementation is more than a mere software implementation (Saka and Chan, 2019). It requires changes in the existing business processes of adopting firms (Abbasnejad et al., 2016). Hence, the theoretical framework of Business Process Change Management (Kettinger \& Grover, 1995) is used to categorize the key enablers of the BIM implementation process. According to this theory "any significant business process change requires a strategic initiative where top managers and leaders define and communicate a vision of change. The organizational environment with a ready culture, a willingness to share knowledge, balanced network relationships, and a capacity to learn, should facilitate the implementation of prescribed process management and change management practices" (Kettinger and Grover, 1995). In the following section, key enablers of BIM implementation are explained in further detail and the role each enabler plays in the BIM implementation process is clearly delineated.

\subsubsection{Strategic initiatives enablers}

The importance of top management support and commitment for the successful implementation of IS (Information Systems)- and IT (Information Technology)-enabled innovations is widely acknowledged by diverse 
researchers (Ragu-Nathan, Apigian, Ragu-Nathan, \& Tu, 2004; Thong, Yap, \& Raman, 1996) and is crucial for the success of BIM implementation, especially during the initial stages (Ahuja et al., 2017; Arayici et al., 2011b; Juan et al., 2017; Mom et al., 2014; Nikas et al., 2007; Ozorhon \& Karahan, 2017; Son et al., 2015; Tsai et al., 2014). A lack of or weak top management support can hinder BIM implementation (Babatunde et al., 2020). Chan et al. (2019a), however, realize that effective organizational management supports and facilitates successful BIM implementation. In the context of this research, top management support is the extent to which top management both perceives the significance of BIM and is involved in the adoption and implementation of BIM processes. This term refers to different aspects such as top management involvement, commitment, support, and top management perception and realisation of BIM benefits. Additionally, managers can use their managerial abilities to overcome the obstacles and/or develop an organizational culture conducive for change (Oliveira \& Martins, 2010).

Top management can facilitate BIM implementation in a variety of different ways. Organizational support positively affects the perceived ease of use and usefulness of BIM among employees (Park et al., 2019). Top management support is also vital for achieving BIM maturity development (Siebelink et al., 2020). A strong top management support can strengthen the initiatives adopted by frontline members to maintain a positive influence over BIM implementation processes (Liao \& Teo, 2019). A higher level of top management support can be applied in order to achieve higher perceived usefulness of BIM systems and their success. The resources and practices associated with BIM implementation, such as the quality and quantity of technical support, reward arrangements, conflict management, and contractual relationships, also require top management attention and commitment (Klein \& Knight, 2005; Liao \& Teo, 2018). Top managers must also focus their attention to the strategic management of resources and technology policies to develop the core technical competencies required for implementation (Gann \& Salter, 2000).

As BIM implementation involves alterations in a wide range of organizational change initiatives regardless of modifications in software, these changes can often amplify resistance among employees (Mohammad et al., 2019). Therefore, top management's commitment towards IT-enabled innovations such as BIM, eagerness to provide essential resources (including human, time and budgetary), and their active involvement in the implementation process is critical (Ling, 2003; Slaughter, 2000; Son et al., 2015). Top managers ought to set new goals and objectives; moreover, new organizational structures, roles and responsibilities must be developed, approved and communicated to the employees, and conflicts should be mediated by, for example, providing motives that are aligned with users' expectations (Ragu-Nathan et al., 2004; Thong, Yap, \& Raman, 1997; Vass \& Gustavsson, 2017). To diminish resistance to change, managers must involve key BIM personnel as early as possible in order to obtain their requirements, comments, reactions and approval (Aranda-Mena, Crawford, Chevez, \& Froese, 2009; Arayici et al., 2011b; Won et al., 2013).

As the formal organizational leader in the BIM implementation process, the top management level has the ability to harness their power and control mechanisms to monitor and adjust organizational structures. Structural factors such as centralization, complexity, and formalization have the potential to impact how an organization can successfully implement an IT-enabled innovation (Fredrickson, 1986). Additionally, different forms of organizational structures have been identified to influence the successful management of BIM implementation (Olatunji, 2011). According to Olatunji (2011), organizational structures such as matrix, functional, networked, and divisional must adhere to slightly different strategies and patterns when it comes to implementing BIM. For example, in a matrix structure, team members are required to focus more on adopting the firm's policies and strategies for teamwork and multidisciplinary integration. A functional structure model will require the active participation of all stakeholders in understanding industry policies regarding BIM implementation. In a divisional structure model, all aspects associated with BIM guidelines may require further adjustment by different divisions, depending upon the roles they will play in a particular pattern of the BIM implementation process.

A clear vision, strategy, and an implementation plan are prerequisites for successful BIM implementation (Chunduri et al., 2013; Lindblad, 2019; Mason \& Knott, 2016; Succar et al., 2013). BIM vision herein refers to the understanding of the role that BIM should play in the organization as a whole. BIM vision can be regarded as either a "generalized technological promise", "guiding vision" or a "promotional metaphor" to transform the organization (Miettinen \& Paavola, 2014). These visions guide BIM initiatives in AEC firms.

The BIM vision should then guide and be echoed in the overall BIM strategy, objectives and plans. Developing a strategic plan, decision making criteria, and strategic control mechanisms are key elements of improving BIM implementation (Koseoglu et al., 2019). An inappropriate BIM adoption strategy that is unaligned with the vision 
and that then fails to formulate BIM objectives aligned to vision, strategy, and market evaluation may result in a waste of time and resources (Ghaffarianhoseini et al., 2016). A clear and strategic BIM vision and objectives definition assists companies to concentrate on success criteria identification and to dually track the main goals and benefits (Khosrowshahi \& Arayici, 2012; Ma et al., 2019). The vision, as an effective solution for a range of issues, must be coherent, integrative and broad enough to be interpreted by the variety of interrelated actors involved (Linderoth, 2010). In addition, it must be satisfactorily powerful to engender commitment and must also be based on realistic factors such as market, economic and regulatory conditions (Wilson, 1992).

It is widely stressed that BIM is more than just an IT-software solution. It is critical for organizations to have a clear understanding of how BIM adoption can help them achieve their organizational goals and objectives. Without this, organizations may fail to reap the manifold BIM benefits possible.

Furthermore, various stakeholders may have diverse perceptions, interpretations, and priorities of and regarding BIM. Understanding the possible impact of BIM on a particular stakeholders' interest can aid managers in overseeing BIM implementation more effectively and efficiently (Arayici et al., 2011a; Husain et al., 2018). Moreover, the BIM-enabled business process is reliant on what is considered to be BIM (Ayyaz et al., 2012). Different actors resort to different meanings of 'BIM' which can obscure the unique characteristics and real benefits of BIM amongst BIM and non-construction parties (Barlish \& Sullivan, 2012; Mehran, 2016). Most organizations treat BIM as a tool that completes their conventional methods of creating, storing, viewing and exchanging information (Ayyaz et al., 2012). Defining the BIM in practice and clarifying its scope during the implementation planning can help to eliminate this obscurity.

A BIM implementation plan may include information about some key aspects such as BIM implementation goals and objectives, BIM related roles and responsibilities, the scope of BIM implementation, the process flow for BIM tasks, a timeframe, and supportive organizational and technical infrastructures. A structured training plan which includes expected training requirements and resources should also be established in conjunction with a BIM implementation plan. As the complexity of BIM has the potential to inhibit its adoption (Chen et al., 2019), a costrisk-benefit analysis can be included in the implementation plan of a firm to make sure that the investment will increase its profit (Mom et al., 2014).

Further, a set of BIM corporate policy documents should be developed. These documents may include aspects such as BIM standards and guidelines, BIM uses and mandates on projects, BIM Management Plan content, collaboration procedures, modelling requirements, documentation standards and digital deliverable. Incompatible BIM standards, policies and procedures often inhibit collaboration within organizations and across the boundaries of organizations (Shang \& Shen, 2014). BIM policy documents are commonly considered the governance mechanisms to guide and control BIM implementation efforts. It is vital to distinguish between BIM implementation plans and policies. BIM policies (guidelines, standards, etc.) are written documents to establish the BIM practices for given process areas which do not deal with implementation details, but rather are used as a set of guiding practices (descriptive and/or prescriptive) that a particular AEC firm is expected to comply with in order to ensure sustained performance.

Various BIM-authoring technologies and software packages are available in the market globally (Lu et al., 2017). BIM software selection is an intimidating process as some of the AEC firms are unfamiliar about the factors to consider. In addition, this decision-making process is time-consuming because the availability of large number of BIM-authoring software with different features makes it a lenghty aan challenging process. It is also ambiguous since employees have different perceptions and attitudes towards these sets of software packages (Arayici et al., 2011b). Therefore, proper BIM vendor selection during the initial planning stages is crucial (Tsai et al., 2014; Won et al., 2013). The selection of a BIM vendor or tool must be aligned with the specific requirements of a company's business process and strategy (Aranda-Mena et al., 2009; Khosrowshahi \& Arayici, 2012). A suitable vendor can influence sub-processes of BIM implementation by offering effective training and education, troubleshooting support, and feedback mechanisms (Sepasgozar et al., 2018). BIM vendor involvement and support therefore positively shapes BIM implementation (Mahamadu et al., 2017).

Despite selecting a competent vendor, the management team also needs to choose proper BIM projects in order to truly realize the benefits of BIM. BIM must not be considered as a pre-defined solution, but rather should be identified as a solution to a set of problems (Arayici et al., 2012; Popov, Juocevicius, Migilinskas, Ustinovichius, $\&$ Mikalauskas, 2010). 


\subsubsection{Cultural readiness enablers}

Throughout the BIM implementation process, there are two major continuum mechanisms that impact the application and contextualization of organizational BIM implementation enablers. The first of these two mechanisms is organizational structure, which should be treated as a guiding mechanism and involves aspects such as BIM strategy, the degree of centralization and formalization of organizational structure, and different structural forms such as matrix, functional and divisional. The second one is organizational culture which should be viewed as a driving mechanism and includes aspects such as norms, behaviours and beliefs (Figure 1). When substantial change takes place within an organization, the organizational members may not realize the need for change. Some organizations harbour a fear-based culture; mistakes and errors are not allowed, and employees become used to concealing their errors. However, BIM as an innovation flourishes in an open and safe environment (Grilo \& Jardim-Goncalves, 2010) if mistakes are allowed to be seen as improvement opportunities (Abbasnejad et al., 2016).

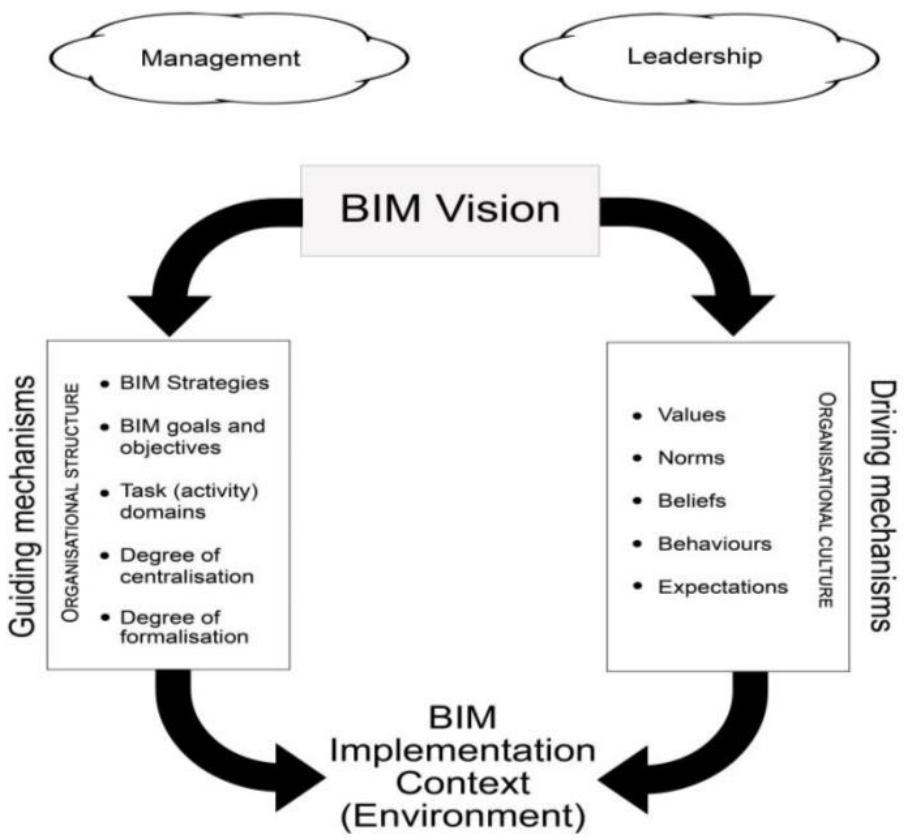

FIG. 1: The roles and significance of organizational culture and structure in the BIM implementation process

Organizational culture comprises norms, beliefs, values, and behaviors and has been considered as a driving mechanism through which organizational members are able to respond to external adaptation and internal integration (Schein, 1985). Cultural readiness can lessen the need for a highly structured environment to stimulate the desired attitude for BIM implementation. The development of organizational culture is a socio-dynamic process and considered as "an emergent property of informal relationships within work groups" (Krackhardt \& Kilduff, 1990). This might be naturally formed regardless of the BIM leader's influence, though it can be heavily shaped by leadership and/or management behaviours and involvements (Schein, 1985). While organizations may develop a relatively homogeneous culture (Peters \& Waterman, 1982), divergent sub-cultures may evolve over time for particular divisions or sub-groups inside the organization (Gregory, 1983). These shared interpretations are crucial to respond to the disagreements.

A critical factor for satisfactory organizational performance is the users' acceptance of BIM tools and systems (Lee et al., 2015; Wang \& Song, 2017). Thus, the sources of resistance must be identified and analysed by BIM leaders of the organization. They also must employ the applicable set of strategies to combat this resistance. They may act as an agent of change to create an environment conducive for change to take place (Bin Zakaria et al., 2013). The scope of leadership goes beyond the scope of commitment (Kotterman, 2006). Supportive and committed managers may employ their power to address a number of concerns throughout the BIM implementation process, however this does not necessarily imply that they are the only leaders of this process. BIM initiation can either take a top-down 'push', middle-out (middle-up-down), 'push-pull' or bottom-up 'pull' approach (Figure 2) (Succar \& Kassem, 2015). Extending these approaches to organizational context implies that 
the BIM emerging leaders (otherwise known as initiators) might be the front-liner employees or middle managers rather than top managers. The BIM emerging leaders are most likely to play a leadership role in a number of BIM implementation aspects such as communicating to software vendors, training and supervising potential adopters, leading BIM pilot projects and developing BIM policies and plans. As they may be on the frontlines or in the middle management tier of the organizational hierarchy, they may initially demonstrate an informal or emerging leadership structure and might not identify as BIM leaders per se.

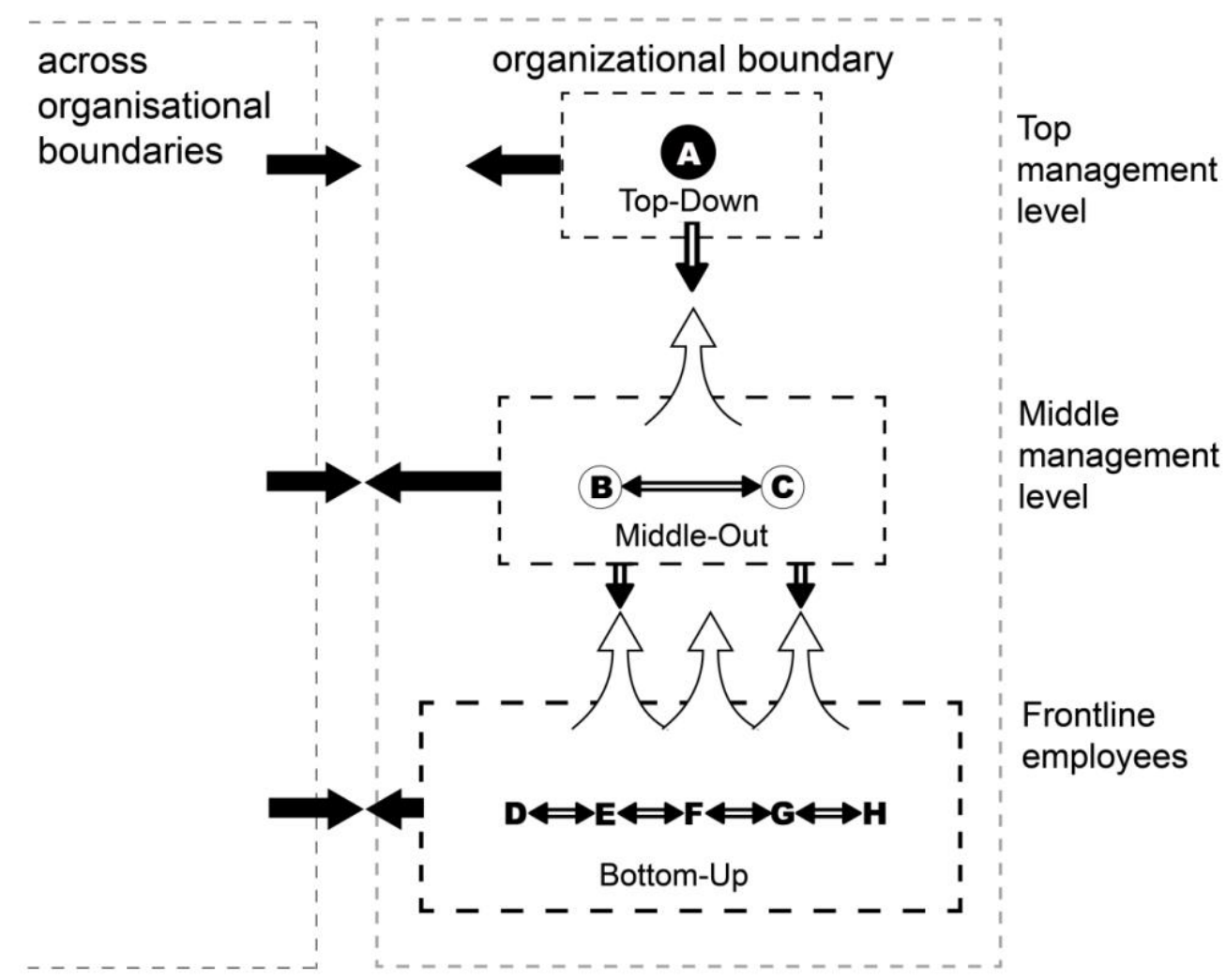

FIG.2: Organizational BIM adoption approaches (Adapted from Succar \& Kassem, 2015)

Kay (2004) describes that to optimize the results, effective leadership style, namely directing, teaching-coaching, facilitating, and delegating styles, requires identifying team members' preferences, expectations and competencies as well as situational conditions. Accordingly, he identifies the effective leadership styles based on these variables as the following:

- Directing style: appropriate in situations where team members possess minimal knowledge, skill and/or experience.

- Teaching-coaching style: applicable in situations where team members have a moderately low level of knowledge and/or skill and/or experience.

- Facilitating style: appropriate where the team members have the knowledge, and skills to complete a task but lack organizational level skills and/or experience and/or confidence to work independently.

- Delegating style: appropriate where team members possess expertise i.e. high level of knowledge, skills, experience and motivation to complete a task to an outstanding level.

When a significant change occurs inside an organization, the organizational practitioners are afraid of the unknown and might not realize the need for change. Some organizations have fear-based culture; mistakes and errors are not allowed, and employees are used to hiding errors. As a part of successful BIM implementation, users should be involved within the implementation process and informed in advance about the necessity of the change (Henderson \& Ruikar, 2010). This will increase the likelihood of BIM acceptance. If the practitioners do embrace BIM as an opportunity to enhance their job and are well-informed about the potential it can have on their work, they are most likely to form a positive attitude towards its use. 
In an organization where the culture of the employees is to share common values and goals and be receptive to change, BIM implementation is more likely to successfully take place. The introduction of BIM is usually followed by some changes which may cause resistance (Shang \& Shen, 2014), or resentment that must be addressed through continual communication among senior managers, employees and project teams. Effective communication is critical to BIM implementation (Ahn et al., 2016; Dossick \& Neff, 2010). Specifically, knowledge exchange is one of the most useful factors facilitating BIM implementation (Vidalakis et al., 2020). In terms of effective communication, individuals feel more involved in the implementation process if they are well-informed about the organizational processes, expectations as well as strategic and tactical goals. Managers must involve key functions and users as early as possible and users' input must be managed for obtaining their requirements, comments, reactions, and approval (Miettinen \& Paavola, 2014; Won et al., 2013). If the interoperable environment is insufficient, the cost and time of information exchange and communications is likely to increase substantially (Chan et al., 2019b).

Knowledge sharing and communication play a pivotal role in alleviating resistance to change and reducing the risk and uncertainty associated with new systems, processes, and technologies (Fidler \& Johnson, 1984). Through improved communication and collaboration with other participants and stakeholders, knowledge sharing is considered as an enabler for BIM implementation (Musa, 2019). Communication and information sharing help to improve transparency and mutual understanding amongst organizational members and different working groups. A collaboration mechanism which is based on mutual trust and transparency with supply chain partners is also one of the key enablers to internal and external alignment (Christopher \& Gattorna, 2005) and collaborative planning. It is not enough to simply share information - the information at hand must be of the highest quality. This is achieved by sharing relevant, accurate and sufficient information in a timely manner. Further, in the context of construction information-demanding supply chain, it is essential for any AEC firm to not become embroiled with too much information. Hence, an important consideration is the information processing capability of AEC firms. Without this, it is difficult to capture the value of shared information and it would likely impact on the effectiveness and willingness of both internal and external members. Thus, it is vital to understand the value of information and how shared information should be processed and delivered to the relevant parties in order to improve both intraorganizational and inter-organizational performance. The Lifecycle Information Transformation and Exchange (LITE) framework can be used as a basis for defining, managing, and integrating information pertaining to both digital and physical assets (Succar \& Poirier, 2020). IT and ICT (Information and Communication Technology) tools, such as cloud computing and the Internet, can also be utilized extensively to increase the knowledge sharing capability of an organization. Knowledge sharing necessarily entails the dissemination of employees' work-related experiences among individuals, groups, and organizations.

\subsubsection{Change management and learning capacity enablers}

A key enabler of BIM implementation is creating and maintaining an environment conducive to enhanced learning capacity. organizations refer to learning orientation as "the presence of interrelated practices and beliefs within an organization that enable employees to develop their own skills and learning. In such an environment, employees do not feel constrained by a fear of failure and willingly participate in experimentation and risk-taking" (Klein \& Knight, 2005).

BIM education in addition to knowledge, skills, competencies, and competitive edge enable individuals to maintain their education and must be continually developed as a BIM implementation strategy (Olugboyega \& Windapo, 2019). Kokkonen and Alin (2016) emphasise the importance of reflective learning and learning from past experiences when BIM-related organizational changes are implemented, labelling them as "deconstruction" and "reconstruction". Deconstruction occurs when the change necessitates different concepts of work and is "a type of reflection in a situation where usually the new way of performing work is relatively different". On the other hand, reconstruction "is based on the idea of correcting something for the better and thus easier to put in practice and changes are seen as an improvement". Likewise, it is discussed that through "learning-by-doing" (learning-byexperimenting), members can ascertain how further efficiencies can be executed through BIM implementation (Arayici et al., 2011b; Arayici et al., 2012). A pilot project is a way of allowing the occurrence of learning-bydoing. Companies then must link the lessons from the pilot projects to their strategy and guidance.

Sufficient and well-designed training helps to develop and enhance staff skills and additionally, expands their understanding of BIM concepts and tools (Ahn et al., 2016). The design and development stages of a typical training and development program include the creation of a learning environment, ensuring transfer of training, 
and developing an evaluation plan (Seyler et al., 1998). The initial formal training must be provided either inhouse or through external sources such as consultants and vendors (Gledson, 2016; Olatunji, 2011). It is important that this is backed by ongoing training and on-the-job support; this is essential to meet end-users' needs after initial implementation has taken place (Mishchenko et al., 2018). After initial implementation, a support is substantial to meet users' requirements. This support can be obtained from eternal organizations or internal colleagues. To incentivise the use of BIM tools, BIM users can be remunerated by either a pay raise or through increased job performance (Howard et al., 2017).

For better knowledge acquisition and learning processes, successful organizations also develop informal learning networks in the form of community of practices. Community of practices (COPs), which is defined as "groups of people who share a concern or a passion for something they do and learn how to do it better as they interact regularly" (Wenger, McDermott, \& Snyder, 2002), helps companies to leverage the tacit knowledge that is embedded in individuals. Successful organizations also facilitate an environment for members to share knowledge and learn from their experiences (Arayici et al., 2011b).

Successful completion of BIM task domains, particularly the complex tasks, is partly dependent on the structure and design of tasks and partly reliant upon the resources allocated to the learners as well as competencies of individuals responsible to complete the task. To create a learning environment and enhance the learning capacity of the companies, competencies of their candidates must be identified, measured and tracked (Boud, 2013). This is an inevitable result in existing BIM-enabled firms (Dakhil et al., 2019). The competency of individuals in delivering BIM-related outcomes provides organizations with valuable information to understand the strengths and weaknesses, unique skill set requirements and human resource allocation, thereby allowing organizations to optimise the quality and objectivity in the selection of more appropriate individuals if need be (Wu \& Issa, 2014). According to Succar et al. (2013), competency assessment of individuals provides organizations with the necessary information to (i) identify the knowledge and experience of employees; (ii) identify individuals who need training in the topics needed; (iii) guide individuals to seek the help of others when necessary; (iv) evaluate employment applicants; and (v) match competency to specific roles or project requirements. Individual competency assessment can also form the basis for certification procedures (Lysaght \& Altschuld, 2000) that may be required to increase the efficiency of their post-construction BIM operations (Giel \& Issa, 2016). As a BIM qualification assessment, an individual competency certification can be used as a recognition of the key expertise within the industry.

\subsubsection{Network relationships enablers}

Successful BIM implementation relies on establishing both internal and external relationships among all parties involved (Merschbrock et al., 2018). Notions of communication, coordination, collaboration and integration are central to network relationships. Organizational integration is defined as "the extent to which distinct and interdependent organizational components constitute a unified whole" (Barki \& Pinsonneault, (2005). Barki \& Pinsonneault (2005) identified barriers of integration as (1) different functional specialization and competencies (domain-specific skills, knowledge and procedures) of team members; (2) frames of reference (shared cognitive structures, tacit knowledge, assumptions, expertise and expectations); and (3) power struggles. Accordingly, mechanisms for integration are identified as mutual adjustment, direct supervision (mentoring), standardization of tasks and procedures, standardization of competency assessment and development, and standardization of values, beliefs and expectations. The successful application of these mechanisms depends upon the variables of task complexity and task interdependence.

It is required for the organizations implementing BIM to collaboratively and coordinately work with external vendors (Arayici et al., 2011b), consultants (Sebastian \& van Berlo, 2010), supply chain partners (Papadonikolaki, Verbraeck, \& Wamelink, 2017; Papadonikolaki et al., 2016) and internal divisions such as research and development (R\&D) (Cerovsek, 2011), human resources, and Information Technology (IT) in order to effectively deal with information exchange and integration aspects, as well as the problems associated with the system and software (Figure 3). Moreover, factors such as corporate compatibility, inter-firm knowledge mobility, and interfirm power dynamics require inter-organizational alignment in order to positively transform the BIM implementation process (Papadonikolaki, 2018). The availability of high-quality external parties, such as consultants and software vendors, is particularly important and essential, especially given that most construction firms are often lacking in the human resources and in-house expertise necessary for BIM implementation. The duties of a consultant may include introducing requirements and analysis of business needs, developing protocols and documentation, recommending suitable computer hardware and software, ensuring usability of the BIM 
model, bearing their share of BIM implementation costs (Liao et al., 2019), and managing and controlling the implementation process itself. Moreover, the vendors can provide computer hardware and software, user training, and technical support. At times, software vendors may play the consultant role as well (Won et al., 2013). R\&D within the company can also help to provide innovative solutions to overcome the problems and bottlenecks that may arise from the BIM implementation process (Cerovsek, 2011). When considered and employed together, these aspects have the potential to promote a static, trained organization transcend into one capable of learning and continued development.

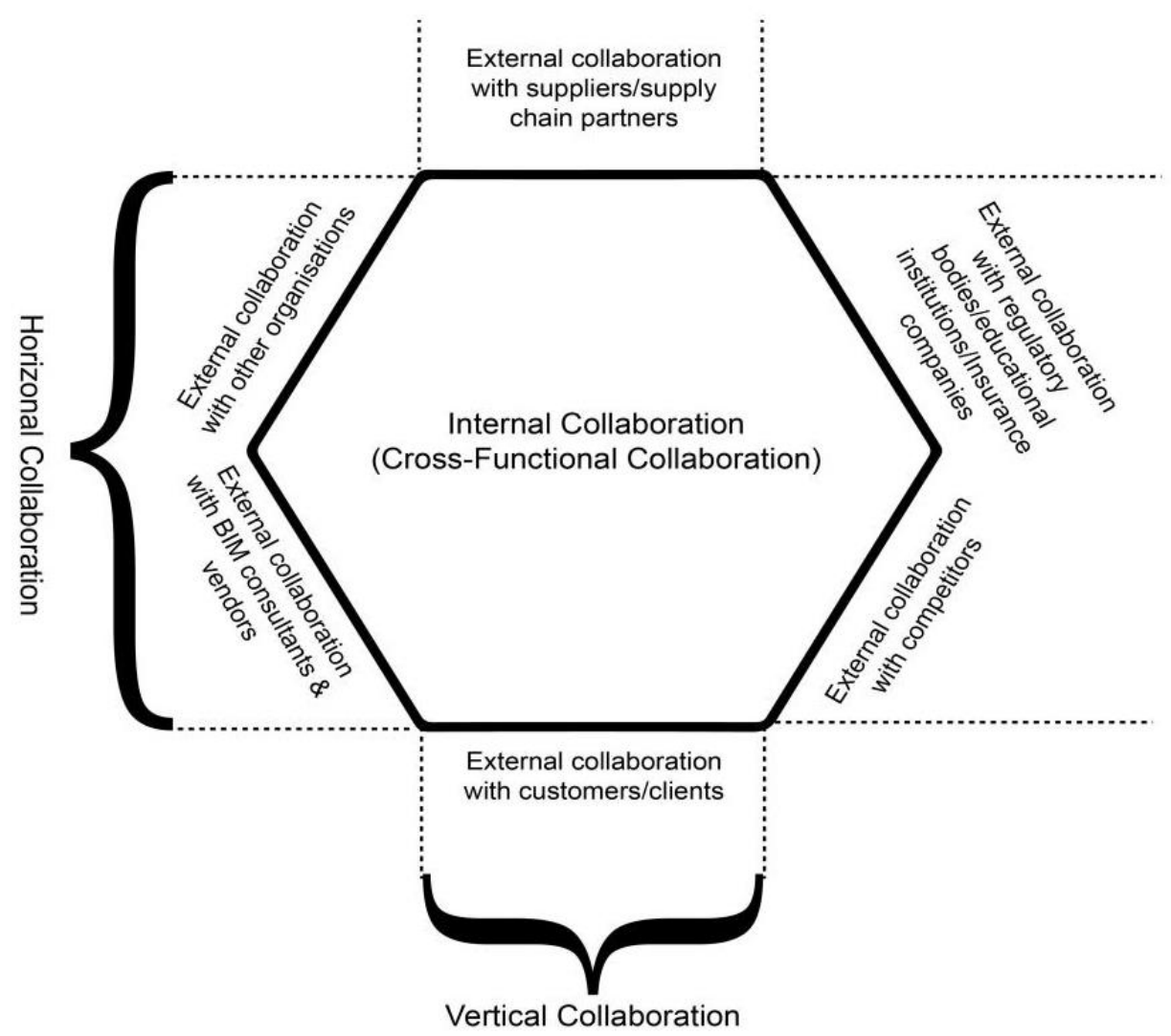

FIG. 3: Intra- and Inter-organizational collaborative network relationships in the context of BIM implementation

\subsubsection{Process and performance management enablers}

Companies aiming to adopt BIM must continuously improve their BIM performance and make progress towards continuous process and performance improvement, despite the fact that measuring their performance may entail considerable time and human effort (in the form of collecting and providing the necessary information) (Choi et al., 2018). Inadequate BIM performance measurement can inhibit its adoption (Shin \& Choi, 2016). Process and performance management tools can be categorised in different taxonomies including (1) those that aim to measure the status of BIM implementation within the internal context of organizations and projects such as capability and maturity assessment tools; (2) those that aim to facilitate the external benchmarking such as BIM cloud score (Du et al., 2014); and (3) those that aim to determine the effectiveness of BIM implementation efforts such as BIM benefit assessment/management tools.

Several organizational maturity assessment tools have been developed for assessing an enterprise's performance in BIM utilization (Wu et al., 2017). Maturity assessment tools are used to measure BIM performance and to move towards continuous improvement (Liang et al., 2016; Sebastian \& van Berlo, 2010; Succar et al., 2012). The Capability maturity model, for instance, contains mechanisms that evaluate strengths and weaknesses of adopted companies' capabilities. This structure allows internal and external benchmarking of the company's competencies. The implementation maturity model allows an organization to obtain insights into the current status of its 
implementation processes, both technologically and organizationally, and introduces ways for pursuing the status to be achieved (i.e. a higher maturity level) (Siebelink et al., 2018).

Central to maturity assessment is the concept of process perspective. In process perspective, organizations are considered as a system of processes connected together in an integrated manner (Benner \& Tushman, 2003). Integration is a multidimensional construct and involves collaboration and coordination amongst the different organizational work groups involved to achieve a unity of efforts and additionally, to render organizational processes more strategic in nature (Becker \& Huselid, 2006). While collaboration puts emphasis on aspects such as socialization, group work and interaction between organizational members, coordination deals with the skillful and balanced simultaneous movement of different organizational units and further, adds objectivity to collaborative efforts to ensure they are on track towards achieving the required outcomes. Collaboration is fostered through structural mechanisms such as job sharing, standardized practices, and any work arrangement that promotes flexibility. Coordination is fostered through the deployment of structural mechanisms such as strategic planning, two-way communication channels, and a structure that supports performance assessment and reviews. To enable the linkage of different organizational processes, structural mechanisms such as cross training and shared measurement systems were found to be critical in facilitating inter-process collaboration and coordination.

Additionally, input-process (activities, tasks)-output model underpins the process perspective (Garvin, 1998). In the context of BIM, inputs refer to BIM implementation prerequisites such as BIM tools and software, policy documents (standards, guidelines, etc.), users' requirements and planning initiatives as well as competency development. BIM processes involve all business processes and interactions between BIM users and with BIMauthoring technologies and are inclusive of factors such as communication and information, workflows, and collaboration that facilitate process improvement. BIM-enabled processes can be visualised and analysed through process management techniques such as process mapping and team-based improvement techniques. Outputs are BIM deliverables such as BIM implementation goals and objectives, BIM models as well as quality information. Subsequently, a combination of a number of outputs (such as short-term results and benefits) would lead to an achievement of outcomes (such as long-term goals including BIM vision, increased productivity, client satisfaction, profitability and competitiveness).

Throughout the BIM implementation process, it is also important that companies undertake benchmarking by continuously measuring and comparing one's business processes against those comparable processes demonstrated in other leading organizations. The intention is to obtain the relevant information organizations require to identify and implement sustained improvement (Watson, 1993). The difference between them is that the focus of most maturity evaluation tools is to assess the level of BIM performance within an organization, while external benchmarking tools and metrics allow a comparison between one enterprise's BIM performance and that of their industry peers (Du et al., 2014). Each AEC firm should then meticulously examine their contingencies to appropriately align BIM best practices with their own business processes.

A number of BIM benefit assessment and management tools exist in the extant literature. A benefit can be described as "an outcome whose value is considered advantageous by a stakeholder" (Ward \& Daniel, 2006). Benefit management involves a spectrum of stages including identification, realization, measurement and analysis to enable BIM leaders and managers to distinguish the value-adding and non-value adding processes. Additionally, it enables them to investigate whether and in what process areas improvement actions are required in order to maximize the potential BIM benefits available. It is worth noting that potential BIM benefits may vary from firm to firm depending on how BIM and its strategy has been defined and what success means to each particular firm.

Table. 1: BIM implementation enablers extracted from the extant literature

\begin{tabular}{|l|c|c|c|}
\hline & $\begin{array}{c}\text { BIM } \\
\text { implementation } \\
\text { enablers }\end{array}$ & References & $\# N$ \\
\hline & $\begin{array}{c}\text { Top management } \\
\text { support }\end{array}$ & $\begin{array}{c}\text { Liao \& Teo (2018), Dowsett \& Harty (2019), Juan et al. (2017), } \\
\text { Lines \& Vardireddy (2017), Wang \& Song (2017), Howard et }\end{array}$ & 18 \\
& & al. (2017), Ozorhon \& Karahan (2017), Ahuja et al. (2016), Son \\
& et al. (2015), Sackey et al. (2015), Lee et al. (2015), Poirier et \\
& & al. (2015), Tsai et al. (2014), Imoudu Enegbuma et al. (2014), \\
& & Anker \& Jóhannesson (2013), Arayici et al. (2011b), Arayici et \\
& & al. (2011a), Nikas et al. (2007) & \\
\hline
\end{tabular}




\begin{tabular}{|c|c|c|c|}
\hline & $\begin{array}{c}\text { BIM } \\
\begin{array}{c}\text { implementation } \\
\text { enablers }\end{array} \\
\end{array}$ & References & $\# \mathrm{~N}$ \\
\hline & $\begin{array}{l}\text { Mechanism to } \\
\text { incorporate use's } \\
\text { input }\end{array}$ & $\begin{array}{l}\text { Wang \& Song (2017), Sackey et al. (2015), Lee et al. (2015), } \\
\text { Won et al. (2013), Arayici et al. (2011a) }\end{array}$ & 5 \\
\hline & Strategic vision & $\begin{array}{c}\text { Liao \& Teo (2018), Tsai et al. (2014), Chunduri et al. (2013), } \\
\text { Khosrowshahi \& Arayici (2012), }\end{array}$ & 4 \\
\hline & $\begin{array}{c}\text { Strategic } \\
\text { implementation plan }\end{array}$ & $\begin{array}{c}\text { Lines \& Vardireddy (2017), Wang \& Song (2017), Sackey \& } \\
\text { Akotia (2017), Sackey et al. (2015), Chunduri et al. (2013), } \\
\text { Jung \& Joo (2011), Arayici et al. (2011a), Coates et al. (2010), } \\
\text { Sebastian \& van Berlo (2010) }\end{array}$ & 9 \\
\hline & $\begin{array}{c}\text { Strategic } \\
\text { stakeholder analysis }\end{array}$ & Arayici et al. (2012) & 1 \\
\hline & $\begin{array}{l}\text { cost-benefit-risk } \\
\text { analysis }\end{array}$ & Mom et al. (2014) & 1 \\
\hline & BIM policies & Jung and Joo (2011), Lee et al. (2015), Succar (2009) & 3 \\
\hline & $\begin{array}{c}\text { BIM software } \\
\text { (vendor selection) }\end{array}$ & $\begin{array}{l}\text { Tsai et al. (2014), Won et al. (2013), Aranda-Mena et al. } \\
\text { (2009), Khosrowshahi \& Arayici (2012), Mahamadu et al. } \\
\text { (2017) }\end{array}$ & 5 \\
\hline \multirow{6}{*}{ 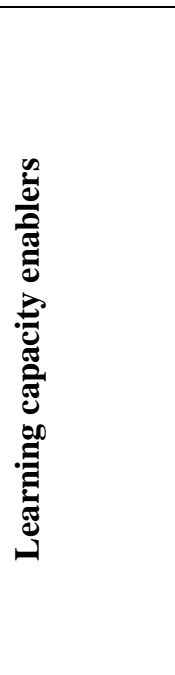 } & Collegial help & Juan et al. (2017), Peansupap \& Walker (2005) & 2 \\
\hline & BIM expertise & $\begin{array}{l}\text { Hosseini et al. (2018), Ozorhon \& Karahan (2017), Ahn et al. } \\
\text { (2016), Ahuja et al. (2016), Sackey et al. (2015), Poirier et al. } \\
\text { (2015), Eadie et al. (2013), Mayo et al. (2012), Ku \& Taiebat } \\
\text { (2011) }\end{array}$ & 9 \\
\hline & $\begin{array}{l}\text { Individual } \\
\text { competency } \\
\text { assessment }\end{array}$ & $\begin{array}{c}\text { Wu et al. (2018a), Wu et al. (2018b), Sackey \& Akotia (2017), } \\
\text { Ozorhon \& Karahan (2017), Pour Rahimian et al. (2014), } \\
\text { Succar et al. (2013), }\end{array}$ & 6 \\
\hline & Learning-by-doing & $\begin{array}{c}\text { Ahuja et al. (2016), Kokkonen \& Alin (2016), Miettinen \& } \\
\text { Paavola (2014), Arayici et al. (2011a) }\end{array}$ & 4 \\
\hline & $\begin{array}{c}\text { Community of } \\
\text { practice }\end{array}$ & Ahn et al. (2016), Peansupap \& Walker (2005) & 2 \\
\hline & $\begin{array}{l}\text { Learning from past } \\
\text { experiences }\end{array}$ & Kokkonen \& Alin (2016), Arayici et al. (2011b) & 2 \\
\hline \multirow{3}{*}{ 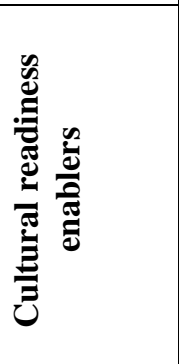 } & $\begin{array}{l}\text { Existence of change } \\
\text { agents }\end{array}$ & $\begin{array}{c}\text { Lines \& Vardireddy (2017), Bin Zakaria et al. (2013), Chunduri } \\
\text { et al. (2013) }\end{array}$ & 3 \\
\hline & $\begin{array}{l}\text { Early user } \\
\text { involvment }\end{array}$ & Liao \& Teo (2018), Miettinen \& Paavola (2014) & 2 \\
\hline & $\begin{array}{l}\text { Open } \\
\text { communication \& } \\
\text { information sharing }\end{array}$ & $\begin{array}{c}\text { Çıdık et al. (2017), Juan et al. (2017), Lines \& Vardireddy } \\
\text { (2017), Ahn et al. (2016), Poirier et al. (2015), Dossick \& Neff } \\
\text { (2010) }\end{array}$ & 6 \\
\hline 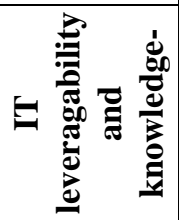 & $\begin{array}{l}\text { BIM-based KM } \\
\text { system }\end{array}$ & $\begin{array}{l}\text { Hong et al. (2019), Ahn et al. (2016), Arayici et al. (2012), Jung } \\
\text { \& Joo (2011), Gu \& London (2010) }\end{array}$ & 5 \\
\hline
\end{tabular}




\begin{tabular}{|c|c|c|c|}
\hline & $\begin{array}{c}\text { BIM } \\
\begin{array}{c}\text { implementation } \\
\text { enablers }\end{array} \\
\end{array}$ & References & $\# \mathrm{~N}$ \\
\hline & $\begin{array}{l}\text { Use of } \\
\text { communication } \\
\text { technologies }\end{array}$ & $\begin{array}{l}\text { Lines \& Vardireddy (2017), Volk et al. (2014), Nikas et al. } \\
\text { (2007) }\end{array}$ & 3 \\
\hline \multirow{2}{*}{ 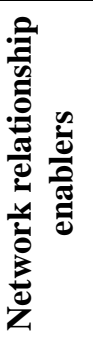 } & $\begin{array}{l}\text { Inter-organisational } \\
\text { linkage }\end{array}$ & $\begin{array}{l}\text { Cao et al. (2018), Dowsett \& Harty (2019), Hosseini et al. } \\
\text { (2018), Papadonikolaki \& Wamelink (2017), Ozorhon \& } \\
\text { Karahan (2017), Papadonikolaki et al. (2016), Jensen \& } \\
\text { Jóhannesson (2013), Homayouni et al. (2010) }\end{array}$ & 8 \\
\hline & $\begin{array}{l}\text { Cross-functional } \\
\text { coordination and } \\
\text { collaboration }\end{array}$ & Sackey et al. (2015), Cerovsek (2011) & 2 \\
\hline \multirow{4}{*}{ 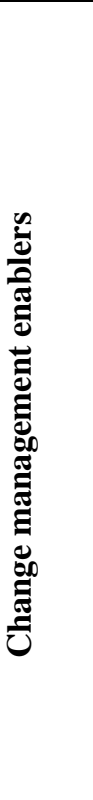 } & $\begin{array}{l}\text { Rewards and } \\
\text { recognition } \\
\text { (incentives) }\end{array}$ & $\begin{array}{l}\text { Ngowtanasuwan \& Hadikusumo (2017), Howard et al. (2017), } \\
\text { Sackey et al. (2015), Olatunji (2011), Peansupap \& Walker } \\
\text { (2005) }\end{array}$ & 5 \\
\hline & $\begin{array}{l}\text { User training and } \\
\text { education }\end{array}$ & $\begin{array}{l}\text { Hong et al. (2019), Siebelink et al. (2018), Wu et al. (2018a), } \\
\text { Wu et al. (2018b), Liao \& Teo (2018), Dowsett \& Harty (2019), } \\
\text { Kudirat \& Adamu (2018), Jin et al. (2017), Lines \& Vardireddy } \\
\text { (2017), Ngowtanasuwan \& Hadikusumo (2017), Juan et al. } \\
\text { (2017), Zhou et al. (2017), Ozorhon \& Karahan (2017), Ahn et } \\
\text { al. (2016), Rogers (2015), Poirier et al. (2015), Sackey et al. } \\
\text { (2015), Tsai et al. (2014), Elmualim \& Gilder (2014), Imoudu } \\
\text { Enegbuma et al. (2014), Samuelson \& Björk (2013), Rezgui et } \\
\text { al. (2013), Bryde et al. (2013), Eadie et al. (2013), } \\
\text { Khosrowshahi \& Arayici (2012), Arayici et al. (2011b), } \\
\text { Olatunji (2011), Gu \& London (2010), Nikas et al. (2007) }\end{array}$ & 30 \\
\hline & $\begin{array}{l}\text { Supportive } \\
\text { supervisor }\end{array}$ & Peansupap \& Walker (2005) & 1 \\
\hline & $\begin{array}{l}\text { Management } \\
\text { readiness for change }\end{array}$ & Juan et al. (2017), Arayici et al. (2011a) & 2 \\
\hline \multirow{3}{*}{ 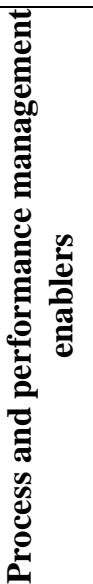 } & $\begin{array}{l}\text { Benchmarking tools/ } \\
\text { metrics }\end{array}$ & $\begin{array}{l}\text { Wu et al. (2018a), Mahamadu et al. (2017), Lines \& Vardireddy } \\
\text { (2017), Liu et al. (2017), Du et al. (2014), Giel \& Issa (2013), } \\
\text { Barlish \& Sullivan (2012), Succar et al. (2012), Coates et al. } \\
\text { (2010), Sebastian \& van Berlo (2010) }\end{array}$ & 10 \\
\hline & $\begin{array}{l}\text { Maturity assessment } \\
\text { tools/ metrics }\end{array}$ & $\begin{array}{l}\text { Siebelink et al. (2018), Mahamadu et al. (2017), Giel \& Issa } \\
\text { (2016), Liang et al. (2016), Chen et al. (2016), Al Ahbabi \& } \\
\text { Alshawi (2015), Kam et al. (2013), Jung \& Joo (2011), Succar } \\
\text { (2010), NIBS (2007) }\end{array}$ & 10 \\
\hline & $\begin{array}{l}\text { Benefit assessment } \\
\text { tools/ metrics }\end{array}$ & Love et al. (2014) & 1 \\
\hline
\end{tabular}




\section{METHODOLOGY}

Selecting the BIM implementation enablers for the ISM analysis was a twofold process. Firstly, the enablers and their frequencies were extracted from the study previously conducted by the first author (Abbasnejad, 2018; Abbasnejad et al., 2020). Secondly, these enablers were discussed with BIM experts through face-to-face interviews and the findings are presented in section 4.1. Eight semi-structured interviews were conducted in a varied sample of industry practitioners and academics with different perspectives. Qualitative feedback and comments were sought to elicit interviewees comments on the organizational BIM implementation enablers and to identify the more critical enablers. This is because ISM methodology is incapable of assessing too many variables (Attrie et al., 2013b).

Enablers which were frequently mentioned in the literature and exactly by BIM experts were used for the ISM analysis directly without any modifications. Other enablers which were mentioned mutually in the interviews, such as "benchmarking tools" and "maturity assessment tools", or "user training and education", "learning-by-doing", and "learning from past experiences", were combined as one particular enabler for the ISM analysis (although they might be from different categories). Enablers which were not emphasized by the experts or received little attention in the extant literature, were not considered in the final ISM analysis. After verifying the enablers, eleven major enablers were selected for the ISM analysis which is presented in Table 2. Lastly, an ISM was developed to analyze the interrelations between the selected enablers. The inputs for this model were the experts' opinions (BIM practitioners) and relations found through literature review. These inputs were then ordered hierarchically and logically using ISM and MICMAC.

Table. 2: Key BIM implementation enablers

\begin{tabular}{|c|c|}
\hline \multicolumn{2}{|c|}{ Selected key BIM implementation enablers } \\
\hline 1 & Communication and Information Sharing \\
\hline 2 & Leadership \\
\hline 3 & BIM Training and Learning \\
\hline 4 & BIM Vision and Strategy \\
\hline 5 & Resource Availability \\
\hline 6 & Motivation \\
\hline 7 & BIM Vendor Selection \\
\hline 8 & BIM Implementation Plan and Policies \\
\hline 9 & Managing Network Relationships \\
\hline 10 & BIM Performance Measurement \\
\hline 11 & Top Management Support \\
\hline
\end{tabular}

ISM was first introduced by Warfield (1976) to model for the analysis of complex socioeconomic systems (Verma et al., 2018). This is a qualitative and interpretive method that is used for generating solutions for complex problems by structural mapping of the interconnections between elements (Colin et al., 2011). One benefit of ISM over other methods, such as focus groups and Q-sort, is that ISM minimizes the number of queries required for exploring relationships by using mathematical algorithms (Attrie et al., 2013a). The main characteristics of this method are (Raj et al., 2008):

- ISM is interpretive as the group's judgment determines the relationship of different elements.

- It is based on mutual relationships, and finally it provides an overall structure of complex elements.

- It represents the relationships in a diagraph model.

- It can be used as a group learning process although experts can benefit from it individually.

In the context of BIM, this method has been used to analyze and identify factors affecting BIM adoption in China (Ma et al., 2019) and prioritizes the BIM capabilities of particular organizations (Ahuja et al., 2017). This study adopted ISM to investigate the dynamics of different organizational BIM implementation enablers. ISM consists of five steps which will be elaborated in the following section. Figure 4 presents the process of implementing ISM in this study. 


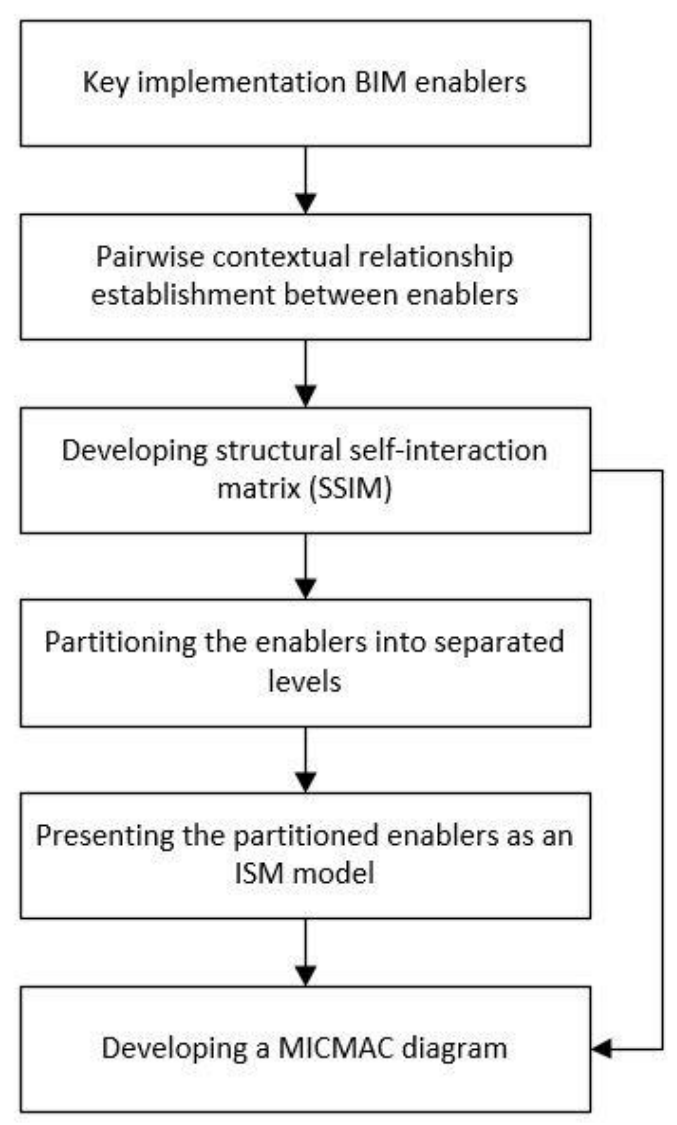

FIG. 4: The process of implementing ISM

\subsection{Leveraging Expert Interviews into Key BIM Implementation Enablers}

Eight expert interviews have been conducted, followed by a desktop analysis where necessary to identify the most critical enablers and their inter-relations. Table 3 provides demographic information about the experts. Each interview took around one hour and took place at a time and place convenient to the interviewees. A short description and overview of the research was provided to each interviewee beforehand. The interview questions were kept deliberately broad so the answer given to each question was not led in any way. Follow-up prompts and probes were utilised to ensure the completeness of the response to interview questions. The interviews were transcribed and analysed using Nvivo software. Both the open coding and pre-defined coding approach were utilised to evaluate the data. Open coding was initially used to check if any new code would emerge followed by a pre-defined coding based on the identified enablers. This helped the research team to manage and summarise the amount of data. The key findings of the interviews are presented below.

Table. 3: Demographic information of interviewees

\begin{tabular}{|c|c|c|c|c|}
\hline Code & Designation & Discipline Area & Industrial Experience & BIM Experience \\
\hline I1 & BIM Consultant (E) & Architecture & 10 years & 6 years \\
\hline I2 & BIM Vendor Member & Construction management & 20 years & 7 years \\
\hline I3 & BIM Manager & Architecture & 21 years & 7 years \\
\hline I4 & BIM Manager & Urban planning & 15 years & 5 years \\
\hline I5 & National BIM manager & Civil Engineering & 23 years & 3 years \\
\hline I6 & National BIM manager & Mechanical Engineering & 13 years & 7 years \\
\hline I7 & BIM academic & Construction & 3 years & 9 years \\
\hline I8 & BIM academic & Architecture & 4 years & 9 years \\
\hline
\end{tabular}




\section{Communication and Information Sharing}

Implementing BIM requires changes to the way an organisation operates. So, for a smooth transition from a nonBIM to a BIM-based approach, communication is discussed by all interviewees as a key factor in creating a common understanding and a consensus among different stakeholders. As an example Interviewee I5, noted: "Communication is key in terms of overcoming resistance to change, and disseminating the key information throughout the organisation and among the team members. Communication comes down to stakeholders and deliverables, so communicating from very early on is what everybody is expected to do, how they expect to communicate and how often, is very critical".

\section{Leadership}

One of the findings from the interviews was that an individual or a group with power can play the role of change agent to lead the BIM implementation process. BIM leaders can also perform two major types of assessments. An internal assessment to understand current organisational capabilities and competencies, and an external evaluation to assess the organisation's performance within its business environment. "Leaders however usually focused on what is in front of them and need to ensure not to neglect the workload allocated to other personnel. There are some individuals in companies who are eager to adopt BIM tools and tasks earlier on, however, the BIM leaders need to be careful not to overload them" indicated by interviewee I3.

BIM leaders take different roles, responsibilities and styles depending on their competencies and organisational position. For instance, a key leadership skill was to check the quality of BIM training programs as interviewee I6 mentioned: "BIM leaders can critique the training programs and identify anythings that needs improvement. For example, they need to ensure the staffs done the model details right and it is more about steering leadership if they went wrong, then BIM leaders will bring them in line and/or adjust the training requirements".

\section{BIM Training and Learning}

Organisations should assess the current competencies of their members and, based on that, should decide whether they need to recruit any new member for a specific BIM role. Interviewee I2 indicated: "some companies have a very detailed BIM implementation plan and very strict guidelines on how to create BIM models, but still they fail to produce proper BIM models because they do not have the right skill sets. There is not a systematic way of assigning BIM roles. It is typically job interviews and then they will trial them on some work and observe their work closely. They will have to oversee them all the time. Instead they should have done a competency-based training in a more systematic way in the first place".

Some of the experts said that the ways in which some BIM roles are currently allocated in some companies are totally misleading. Interviewee I5 stated: "I have seen some guys end up from being a CAD manager to a BIM manager but they do not understand what BIM is really about; they merely try to think that I have gone from CAD manager to BIM manager, but it is not an automatic transition". In terms of BIM-related training a combination of both formal training and on-the-job training was raised as an effective approach. For example Interviewee I 2 stated "if it is for learning the basics of software itself I would suggest formal training. We need also a BIM expertise for on-the-job training who are usually the early adopters and foster an environment conducive for learning through experience".

\section{BIM Vision and Strategy}

There is a consensus among most of the interviewees that for BIM implementation, an organisational vision should be established, measurable goals and objectives should be defined, and a strategy should be formulated on how to achieve them. It is also critical to "determine the degree to which an organisation will implement BIM and then define transition process for the integration of BIM into their business practices" interviewee I1 mentioned. It was suggested by six interviewees that firms should either align their strategies and vision to BIM related strategies and vision or completely alter them to create new ones. "Once the BIM strategy and vision are in place, usually they will evolve around the lessons learned from previous BIM-enabled projects" indicated by interviewee I3.

\section{Resource availability}

One of the critical aspects of BIM implementation raised by most of the interviewees was about the provision of adequate resources such as financial resources, human resources, technological resources, and organizational resources (policies, protocols, etc.). Interviewee I3 believed that if they were to implement BIM again they would 
probably employ more people so that there will be more expert staff available, and try to use a learning management system so that the resources would be available earlier, and their effectiveness can be evaluated and tracked.

\section{Motivation}

The literature suggests the relevance of providing rewards and incentives as a way of increasing motivation among the resistors. However, it was raised in the interviews that tangible reward systems and recognition were poorly practised by the AEC organisations. "The rewards are self evident in them when contributing to quality works on the projects and being value part of a team so we do not need to give them financial reward or anything of that nature" Interviewee I3 pointed out. Moreover, Interviewee I5 stated that "We have recruited graduates in the field of BIM because they are usually the early adopters, they might be young but have sufficient willingness to uptake BIM tools". "I find it very interesting that young people want to work on and find solutions themselves rather than being told what to do; I find that sort of motivation is a good recipe" interviewee I2 said.

\section{BIM Software Vendor Selection}

Regarding the issue of vendor, the most critical factors highlighted during the interviews were interoperability of data, especially for larger projects, and being able to choose the right vendor to meet the needs of an organisation. Interviewee I4 said: "If you are working on large projects, then you have to consider data interoperability as the first priority; pricing is less of a concern". Moreover, through model federation, choosing a vendor will be even easier in the near future, interviewee I8 pointed out. "the major factor to choose a BIM software vendor is cost and another point is to look at the market dominance because in this case you will take advantage of more compatibility. If you have got compatibility inherent to software that you are using, it takes less risk and cost and skill sets.

\section{BIM Implementation Plan}

One of the most important issues during BIM implementation planning and readiness, as raised during all expert interviews, is to develop a BIM implementation plan. In fact, as one interviewee put it, "it is a plan to integrate BIM within an organisation" interviewee I7 said. Everyone in the organisation or at least a representative of each level should contribute to the development of the BIM implementation plan, and management should fully support it. Interviewee I1 explained, "Once the key people in each company agree on a BIM implementation plan across all divisions/expertise, then they need to communicate that to the staff including those who are working on BIM projects". Organisations should identify potential barriers and strategies as early as possible, and provide a roadmap to assist them in developing a plan for implementation process. Ultimately companies also need to disseminate the plan to the key stakeholders: "Companies then can upload a BIM implementation plan to their website. Publicising this plan helps to ensure stakeholders understand the approach and timescales" interviewee I5.

\section{Top Management Support}

Managers have to encourage employee participation in the process of BIM implementation by facilitating twoway communication and brainstorming sessions with their representatives as highlighted in multiple interviews. For instance, interviewee I3 discussed "Our manager has provided the opportunity to the members to talk about their concerns in regards to the BIM system through leaving his door open and welcome all the staffs to freely communicate their needs and requirements without the need to go through hierarchical procedures". Likewise interviewee I4 indicated "Our top management was committed to BIM uptake and provided adequate time to get used to the new system, BIM tools and software. They provided a number of training courses and tried to identify the potential users. Interviewee I5 mentioned "our top manager has a good understanding of BIM and they put people in the right places and start training people and developing a basic contractual BIM-enabled people".

\section{Network Relationships}

BIM related knowledge is distributed throughout the networks of various disciplines and firms. This makes the management of technical know-how a significant concern for AEC firms. It was raised by some of the interviewees that participation in networking activities such as seminars and conferences was key to further improve their BIMrelated practices. "There are lots of people to talk to; there are lots of examples to follow, and I think our task is to identify other people that have been successful and learn from them. I have learnt a lot from the community of other people who are trying to do similar things, solve similar problems. Providing that sort of learning 
environment for our staff, I think, is rather valuable because they can see, relate and observe what is occurring in other areas" as mentioned by Interviewee I6.

\section{BIM Performance Measurement}

Six interviewees discussed that post-project benchmarking should be used to assess performance of a BIM project delivery system, in order to provide lessons learned and feedback that can be used to establish benchmarks for future comparisons. Key proposed metrics include (1) process related metrics such as RFI, (2) project schedule metrics such as speed of project delivery, and (3) financial metrics such as profitability. Interviewee I8 mentioned "Commonly people tend to check the BIM projects financially against non-BIM approach and also look at the technical performance and requirements. However, there should be some mechanisms to capture lessons learned that is set up in the first instance and there should be time for all stakeholders in the project involved in the lessons learned where they review their strengths, weaknesses, opportunities that the project has faced and build up their knowledge in those phases".

It is also raised in the interviews that a team of experts should measure the maturity and readiness of an organisation for BIM implementation. This is reflected on the discussion by interviewee I8 in which they stated "We need to determine the overall impact of the change on the organisation components and elements, and then determine the current state of readiness in terms of vision, top management support, roadmap, communication, necessity of change, presence of champion, empowerment, education and training". Similarly interviewee I5 said "I have seen many firms that have not done any readiness or maturity assessment at the time of BIM uptake, however, it would be great for them to assess their current maturity and readiness after a few years of experience in using BIM tools and workflows.

\subsection{Establishing Correlation Structure}

After identifying key BIM implementation enablers, a thorough literature review and interviews with BIM experts were conducted to determine the interconnections between them. As the nature of the interviews was complex, the scripts were interpreted to ascertain the relations. Since different professionals made diverse judgments of the interrelations between enablers, the majority of opinions were superseded by minority ones. The findings of the literature review and interviews were the input for the Structural Self-Interacted Matrix (SSIM). In this analysis, the following symbols were used to represent the interrelations between the enablers (i and j) (Singh \& Kant, 2008):

- $\quad \mathrm{V}=$ enabler $\mathrm{i}$ will help to achieve enabler $\mathrm{j}$;

- $\mathrm{A}=$ enabler $\mathrm{j}$ will help to achieve enabler $\mathrm{i}$;

- $\mathrm{X}=$ enablers $\mathrm{i}$ and $\mathrm{j}$ will help to achieve each other;

- $\mathrm{O}=$ enablers $\mathrm{i}$ and $\mathrm{j}$ are unrelated.

Table 4 depicts SSIM of the enablers.

Table. 4: Developed SSIM

\begin{tabular}{|c|c|c|c|c|c|c|c|c|c|c|c|c|}
\hline & Key BIM implementation enablers & 11 & 10 & 9 & 8 & 7 & 6 & 5 & 4 & 3 & 2 & 1 \\
\hline 1 & Communication and Information Sharing & $\mathrm{V}$ & $\mathrm{X}$ & $\mathrm{X}$ & $\mathrm{V}$ & $\mathrm{O}$ & $\mathrm{X}$ & $\mathrm{V}$ & A & $\mathrm{X}$ & $\mathrm{V}$ & - \\
\hline 2 & Leadership & $\mathrm{X}$ & $\mathrm{O}$ & A & A & A & A & $\mathrm{O}$ & A & A & - & \\
\hline 3 & BIM Training and Learning & $\mathrm{V}$ & $\mathrm{X}$ & $\mathrm{V}$ & $\mathrm{V}$ & $\mathrm{X}$ & $\mathrm{X}$ & $\mathrm{V}$ & $\mathrm{V}$ & - & & \\
\hline 4 & BIM Vision and Strategy & $\mathrm{V}$ & A & $\mathrm{A}$ & A & $\mathrm{A}$ & $\mathrm{O}$ & $\mathrm{A}$ & - & & & \\
\hline 5 & Resource Availability & $\mathrm{V}$ & $\mathrm{V}$ & A & $\mathrm{X}$ & A & A & - & & & & \\
\hline 6 & Motivation & $\mathrm{V}$ & $\mathrm{O}$ & $\mathrm{X}$ & $\mathrm{V}$ & $\mathrm{X}$ & - & & & & & \\
\hline 7 & BIM Vendor Selection & $\mathrm{V}$ & $\mathrm{X}$ & $\mathrm{O}$ & $\mathrm{V}$ & - & & & & & & \\
\hline 8 & BIM Implementation Plan and Policies & $\mathrm{V}$ & A & A & - & & & & & & & \\
\hline 9 & Managing Network Relationships & $\mathrm{V}$ & $\mathrm{X}$ & - & & & & & & & & \\
\hline 10 & BIM Performance Measurement & $\mathrm{V}$ & - & & & & & & & & & \\
\hline 11 & Top Management Support & - & & & & & & & & & & \\
\hline
\end{tabular}




\subsection{Reachability Matrix}

The next step is converting the SSIM to a binary matrix, namely the reachability matrix. This matrix is achieved by substituting $\mathrm{V}, \mathrm{A}, \mathrm{X}$, and $\mathrm{O}$ by 1 and 0 as the following rule (Yadav \& Barve, 2015):

- If the (i,j) entry is $V$, the ( $i, j)$ entry becomes 1 and the $(j, i)$ entry becomes 0 in the reachability matrix;

- If the (i,j) entry is $A$, the ( $i, j)$ entry becomes 0 and the $(j, i)$ entry becomes 1 in the reachability matrix;

- If the (i,j) entry is $X$, the ( $(i, j)$ entry becomes 1 and the $(j, i)$ entry becomes 1 in the reachability matrix;

- If the (i,j) entry is $O$, the (i,j) entry becomes 0 and the $(j, i)$ entry becomes 0 in the reachability matrix.

Following the aforementioned rule, the initial reachability matrix is developed. After determining the pairwise direct relations between the enablers, it is found that some enablers have indirect relations through other enablers; these indirect relations are obtained by considering the transitivity. By taking the indirect interrelationships into account, the final reachability matrix is developed. Table 5 depicts the reachability matrix. In this table, "1" indicates the direct relations and " $1 *$ " indicates the indirect relations between two enablers.

Table. 5: Reachability matrix

\begin{tabular}{|c|c|c|c|c|c|c|c|c|c|c|c|c|c|}
\cline { 2 - 12 } \multicolumn{1}{l|}{} & Key BIM implementation enablers & 1 & 2 & 3 & 4 & 5 & 6 & 7 & 8 & 9 & 10 & 11 & $\begin{array}{c}\text { Driving } \\
\text { power }\end{array}$ \\
\hline 1 & Communication and Information Sharing & 1 & 0 & 1 & 0 & 0 & 1 & $1^{*}$ & 0 & 1 & 1 & 0 & 6 \\
\hline 2 & Leadership & 1 & 1 & 1 & 1 & $1^{*}$ & 1 & 1 & 1 & 1 & $1^{*}$ & 1 & 11 \\
\hline 3 & BIM Training and Learning & 1 & 0 & 1 & 0 & 0 & 1 & 1 & 0 & $1^{*}$ & 1 & 0 & 6 \\
\hline 4 & BIM Vision and Strategy & 1 & 0 & 1 & 1 & 1 & $1^{*}$ & 1 & 1 & 1 & 1 & 0 & 9 \\
\hline 5 & Resource Availability & 1 & 0 & 1 & 0 & 1 & 1 & 1 & 1 & 1 & 1 & 0 & 8 \\
\hline 6 & Motivation & 1 & 0 & 1 & 0 & 0 & 1 & 1 & 0 & 1 & $1^{*}$ & 0 & 6 \\
\hline 7 & BIM Vendor Selection & $1 *$ & 0 & 1 & 0 & 0 & 1 & 1 & 0 & $1^{*}$ & 1 & 0 & 6 \\
\hline 8 & BIM Implementation Plan and Policies & 1 & 0 & 1 & 0 & 1 & 1 & 1 & 1 & 1 & 1 & 0 & 8 \\
\hline 9 & Managing Network Relationships & 1 & 0 & 1 & 0 & 0 & 1 & $1^{*}$ & 0 & 1 & 1 & 0 & 6 \\
\hline 10 & BIM Performance Measurement & 1 & 0 & 1 & 0 & 0 & $1^{*}$ & 1 & 0 & 1 & 1 & 0 & 6 \\
\hline 11 & Top Management Support & 1 & 1 & 1 & 1 & 1 & 1 & 1 & 1 & 1 & 1 & 1 & 11 \\
\hline \multicolumn{2}{|c|}{ Dependence power } & 11 & 2 & 11 & 3 & 5 & 11 & 11 & 5 & 11 & 11 & 2 & \\
\end{tabular}

\subsection{Level Partitions}

For partitioning the enablers, two sets need to be introduced, namely a reachability set and an antecedent set. The reachability set indicates that an enabler can influence other enablers, as well as itself, and the antecedent set includes an enabler itself as well as others that affect it (Li et al., 2019). Intersections are the enablers that can both affect and be affected by an enabler from the reachability set. If the reachability and intersection sets of an enabler are the same, that enabler occupies the top level of the ISM hierarchy. This means that the enabler is likely to be affected by others. After identifying the enablers of the top level of the hierarchy, they will be removed from the reachability set. This process is repeated until all enablers are placed in the ISM hierarchy. Table 6 shows the final result of level partitions. From this table, it is concluded that the enablers are separated into four levels which will be depicted through the next step.

Table. 6: Level partitions

\begin{tabular}{|c|c|c|c|c|}
\hline $\begin{array}{c}\text { Key BIM } \\
\text { implementation } \\
\text { enablers }\end{array}$ & Reachability set & Antecedent set & Intersection & Level \\
\hline 1 & $1,3,6,9,10$ & $1,2,4,5,8,11$ & 1,7 & 1 \\
\hline 2 & $1,2,3,4,5,6,7,8,9$, & $1,2,11,12$ & $2,5,10$ & 4 \\
\hline 3 & $10,11,12$ & & 3,9 & 1 \\
\hline 4 & $3,6,7,10$ & $1,2,3,4,5,6,7,8,9,10,11,12$ & 4,6 & 3 \\
\hline 5 & $3,5,6,7,8,9,10$ & $2,4,11,12$ & 5 & 2 \\
\hline
\end{tabular}




\begin{tabular}{|c|c|c|c|c|}
\hline $\begin{array}{c}\text { Key BIM } \\
\text { implementation } \\
\text { enablers }\end{array}$ & Reachability set & Antecedent set & Intersection & Level \\
\hline 6 & $3,6,7,9$ & $1,2,3,5,6,7,8,9,11,12$ & 6,10 & 1 \\
\hline 7 & $3,6,7,10$ & $1,2,3,4,5,6,7,8,10,11$ & $1,7,9$ & 1 \\
\hline 8 & $3,5,6,7,8,9,10$ & $1,2,4,5,8,11$ & 8 & 2 \\
\hline 9 & $3,6,9,10$ & $1,2,3,4,5,6,8,9,10,11,12$ & 7,9 & 1 \\
\hline 10 & $3,7,9,10$ & $1,3,4,7,8,9,10,11$ & $2,5,6,10$, & 1 \\
\hline 11 & $\begin{array}{c}1,2,3,4,5,6,7,8,9, \\
10,11,12\end{array}$ & $1,2,11,12$ & 12 & 4 \\
\hline
\end{tabular}

\subsection{Formation of ISM digraph and model}

After developing the level of partitions, the relations between the enablers can be presented hierarchically. Figure 5 depicts all relations, including direct and indirect, between the enablers. This digraph presents the chain of influence of enablers on each other. In this digraph, an arrow pointing from enabler i to enabler $j$ shows that enabler i directly influences enabler j. A two-way arrow shows a mutual influence between two enablers i and j. Dashed arrows show an indirect influence between two enablers.

Results show that "top management support", and "leadership" are the most fundamental BIM implementation enablers and placed at the lowest level in the hierarchy. "Vision and strategic planning" is the only enabler in the next level of the hierarchy and is linked to "resource availability" and "implementation plan" which are placed on the next level. Enablers at the highest level are "training and learning", "motivation", "vendor selection", "managing network selection", and "performance management". These enablers are influential when other enablers from the lower levels are considered and satisfactorily addressed by practitioners implementing BIM.

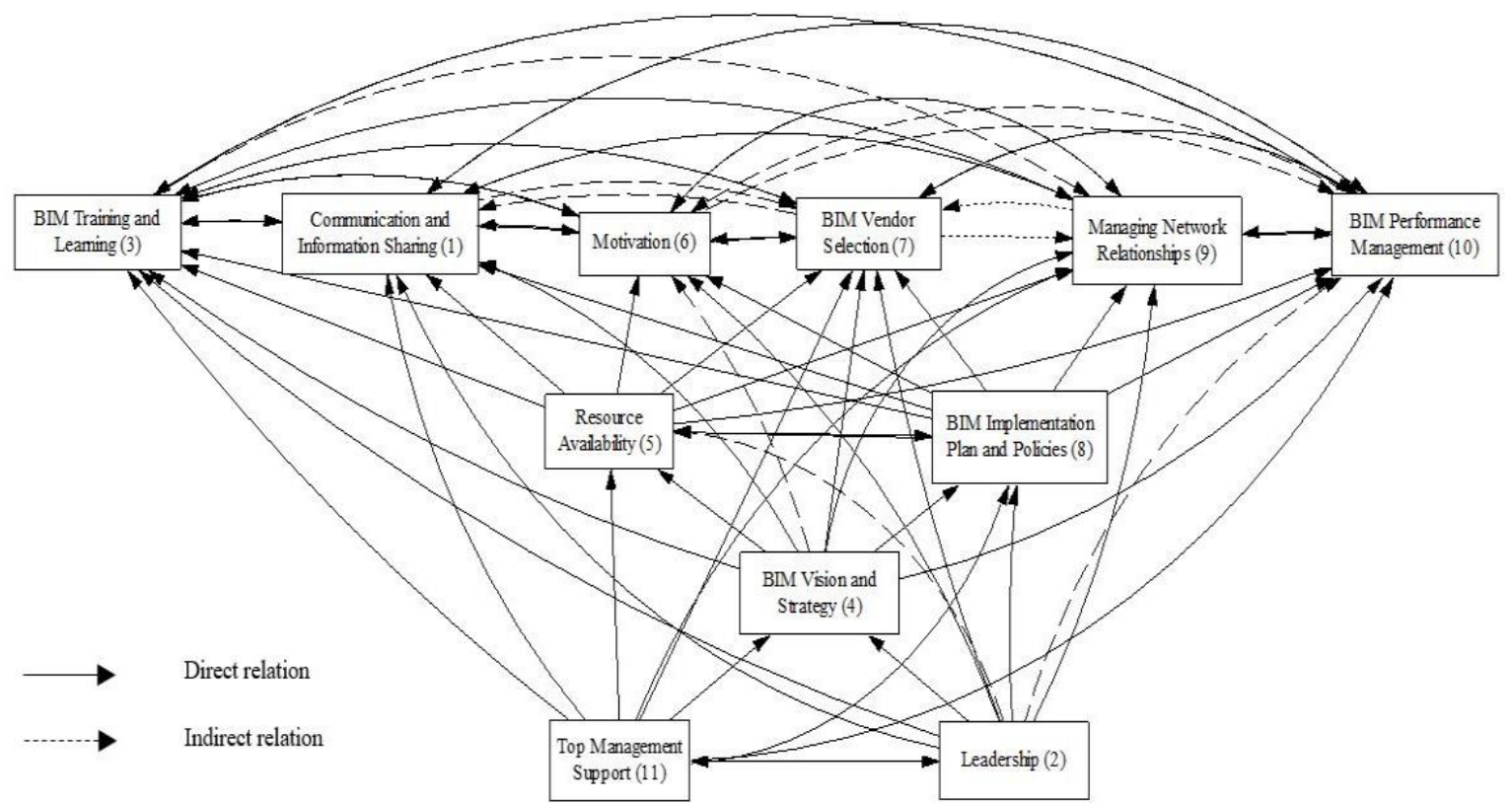

FIG. 5: Interrelations between BIM implementation enablers

\subsection{Classification of enablers (MICMAC analysis)}

The next step is the evaluation of the driving and dependence powers of BIM implementation enablers by transforming the reachability matrix (Table 6) into a MICMAC diagram. The summation of the total number of enablers in row $\mathrm{i}$ (including the enabler $\mathrm{i}$ itself) is the driving power of enabler $\mathrm{i}$, which shows the affecting power 
of the enabler. The summation of the total number of enablers in column i (including the enabler $i$ itself) is the dependence power of the enabler $i$, which shows the power of the enabler being affected by the others (Sarhan et al., 2019). The halves are categorized differently (Saka \& Chan, 2020):

- Autonomous enablers: they are disconnected from the whole system and have few interrelations with other enablers;

- Dependent enablers: they are dependent on other enablers and can be addressed by the related enablers;

- Independent enablers: these are the most significant enablers, in comparison with other enablers;

- Linkage enablers: they affect other enablers and have feedback on themselves.

After calculating the driver and dependence powers of the enablers from Table 5, the MICMAC diagram is drawn (Figure 6).

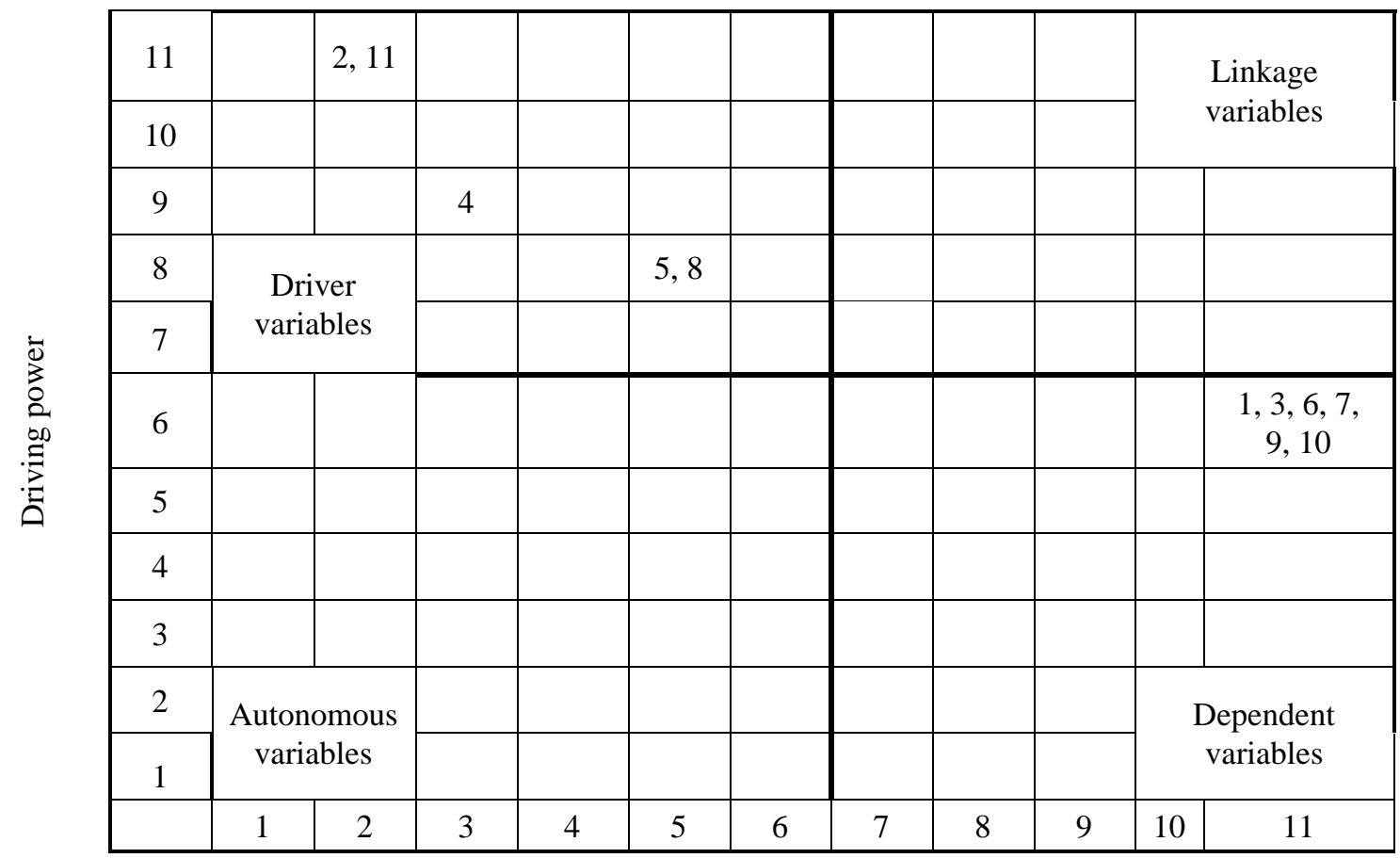

Dependence power

FIG. 6: MICMAC analysis of BIM implementation enablers

As illustrated in Figure 6, five enablers (i.e., 2, 4, 5, 8 and 11) are categorized as driver enablers which indicates that they have a high impact on the other enablers at play. Six other enablers (i.e., 1, 3, 6, 7, 9 and 10) are categorized as dependent enablers, meaning that they are affected by the other enablers at play. No enabler is categorized as autonomous nor linkage, which means that none of them are disconnected from the main system, and none of them separately impact upon top level enablers when an action directs them to.

\section{DISCUSSION}

Through MICMAC analysis, an analysis of BIM implementation enablers in terms of their driving and dependence power has been carried out. There is no enabler in the autonomous cluster on the digraph (Fig. 6). This means that all the enablers are required for the implementation of BIM. Those enablers having higher driving power in the BIM implementation process demand greater priority in the initiation and readiness phases as there are few other dependent enablers that will be impacted by them. The enablers with high driving power are of strategic orientation. On the other hand, dependent enablers are more operational and performance oriented.

It has also been determined that there is no "one-size-fits-all" approach to BIM implementation (Almuntaser et al., 2018). The stimuli of BIM adoption ranges from firm to firm depending on mandates with high urgency to highly proactive approaches. The interrelationships among these enablers will be discussed herein based on the different scenarios that occurred in regards to the BIM adoption and implementation process. Top management support is 
found to be one of the enablers with a high driving impact on a number of other key BIM implementation enablers. Top management responses to BIM initiatives could range from highly negative, to neutral, to highly supportive. Negative responses to BIM initiatives may stem from top management where the management approach is strictly hierarchical, risk averse or otherwise originates from a lack of proper knowledge and understanding about BIM workflows and benefits. In instances where top management forms a highly negative attitude towards BIM tools and concepts, BIM adoption may fail and BIM emerging leaders may abandon the participating organizations. Contrastingly, a supportive stance requires top management to create an organizational culture and climate conducive for BIM implementation; one that comprises the necessary communication channels and resources and that facilitates experimentation. Top management has the potential to recognize staff' initiatives and welcome staff' ideas to assess whether they can be incorporated as part of BIM policies and broader framework. Some types of recognition can be financial reward and occupational promotion. Additionally, as formal organizational leaders, top managers can leverage informal leadership to drive the institutional change required for successful BIM implementation, thereby achieving a bottom-up/top-down implementation approach and allowing for the advancement of organizational-wide BIM adoption and implementation. BIM leaders and top management can rely more on informal communication channels and explicit guidance rather than the traditional hierarchical chain of command.

As aforementioned, BIM initiation and implementation can take a bottom up approach. Top management can either support or stifle the BIM implementation process initiated from the bottom levels. If top management distrusts the bottom-up BIM emerging leaders, they may obstruct the overall implementation process. If top management exhibits a negative attitude towards BIM adoption, emerging leaders may use the initial BIM implementation's tangible successes and benefits to obtain the management support required in providing adequate resources to the BIM implementation process. Another challenge faced by emerging BIM leaders can be located in involving the employees in the BIM implementation process. While early adopters are willing to quickly learn and apply BIM practices, later adopters may require additional support. A strategy that can be taken by BIM emerging leaders is to collect information from BIM pilot projects and case studies to demonstrate and discuss the proven tools and concepts with the skeptical. Effective communication and information sharing mechanisms help for the creation of new meaning and acceptance of BIM tools and concepts among resistors. Ultimately, there is an integral need for BIM emerging leaders to utilize the effective communication channels available in order to ascertain the need for change. This will result in diminishing the initial resistance to change and assist in leveraging additional resources and organizational adoption of BIM. As they are on the frontlines or in the middle management within the overarching organizational hierarchy, leaders may initially demonstrate an informal or emerging leadership structure. By the time informal BIM leaders receive more credibility and visibility within the organization, they may be promoted to more formal leadership roles. Successful BIM implementation has the capacity to create opportunities for the emerging leaders to receive visibility and credibility beyond their own organizational boundaries and also provides opportunities for the entire organization to achieve a competitive advantage in the market.

BIM initiation and implementation can also take a middle-out approach. Such an approach requires middle management level upward leadership and downward influence to achieve effective alignment of the organizational and operational activities associated with the BIM vision and strategy. They aid in facilitating the need for change in communications with the top tiers of management and enable change implementation through leveraging interactions with frontline employees (Belasen \& Frank, 2010; Kuyvenhoven \& Buss, 2011). Middle managers have the potential to bridge informational gaps between the top management levels and frontline employees that might otherwise impede successful BIM implementation (especially in large enterprises with more complex hierarchical structures). They may also have to deal with the process of managing collaboration with external sources. Overall, middle managers can influence BIM implementation by diffusing and synthesizing information both within and across organizational boundaries and mediating between strategy and day-to-day operational activities. If a close and collaborative relationship is established between BIM leaders and the top management level, bottom-up and middle-out implementation approaches may allow for a more comprehensive BIM diffusion and implementation process, and additionally advance BIM implementation efforts in a shorter timeframe.

Leadership is found to be as one the fundamental enablers for BIM implementation that impacts a number of other enablers throughout. BIM leadership may evolve in different phases such as initiation and transition, readiness, the actual implementation as well as improvement. Throughout each of these phases, the BIM implementation team responds to different needs and expectations. For example, during the initiation and readiness phase, BIM 
leadership may face significant resistance to change among employees and/or within top management levels. Further, in the planning and readiness phase, BIM leadership can play a key role in the process of BIM software vendor selection. From the operational and performance point of view, BIM leaders need to assess aspects such as training, support and maintenance to select a proper software vendor. For example, BIM leaders should take the results of individual competency assessments to employ an effective leadership style. This can take the form of directive, teaching-coaching, facilitating and/or delegating.

From the strategic perspective, BIM leaders may develop strategies, such as collaboration and/or negotiation with BIM software vendors and external consultants that affect the flow of information and the depth of knowledge received to organizations about BIM implementation matters. Additionally, BIM leaders with the ability to establish and maintain long-term relationships with external entities such as software vendors and consultants based on mutual trust are more likely to be successful in the BIM implementation process. Arguably, interorganizational networks can be created as a strategy for knowledge and information exchange throughout the BIM implementation process, resulting in increased effectiveness, innovation, collaboration, integration and higher overall success.

In the context of BIM, a critical responsibility of the leaders and top managers involved is to establish the firm's strategic vision to give direction to BIM implementation efforts. Establishing a BIM vision as a means to merely promote technological capabilities negates the role of human and social requirements within the BIM implementation process. In addition, considering BIM as a reaction to the need for cost reduction and/or control leaves the organization open to viewing BIM as an expense that should be stringently monitored and managed (Miettinen \& Paavola, 2014). Therefore, this may limit the resources allocated to BIM implementation and discourage its capabilities to change business processes. In contrast, an organization with a promotional and transformational vision that considers BIM a key driver of its value proposition is more likely to view BIM as a critical organizational resource with the power to improve business processes. Obtaining strategic improvement in the light of BIM functionalities, rather than viewing BIM for mere cost reduction, is the priority. Accordingly, it is more likely for AEC firms to allocate adequate resources to the BIM implementation process. In turn, the availability of resources impacts cultural readiness through increasing the employees' motivation and willingness as well as tolerance for risk (Hess et al., 2012), thereby accelerating BIM implementation efforts. Through the provision of adequate resources and a supportive working environment, firms will find themselves more equipped to increase willingness and innovation as well as in enabling organizational members to continuously and eagerly experiment in different ways of enhancing BIM processes. It is essential that prior to the allocation of resources and to aid for developing a rigorous BIM implementation plan which is aligned with the BIM-enabled vision and strategy, AEC organizations need to measure levels of readiness for change by measuring its internal capabilities inclusive of the competency of BIM actors (Figure 7).

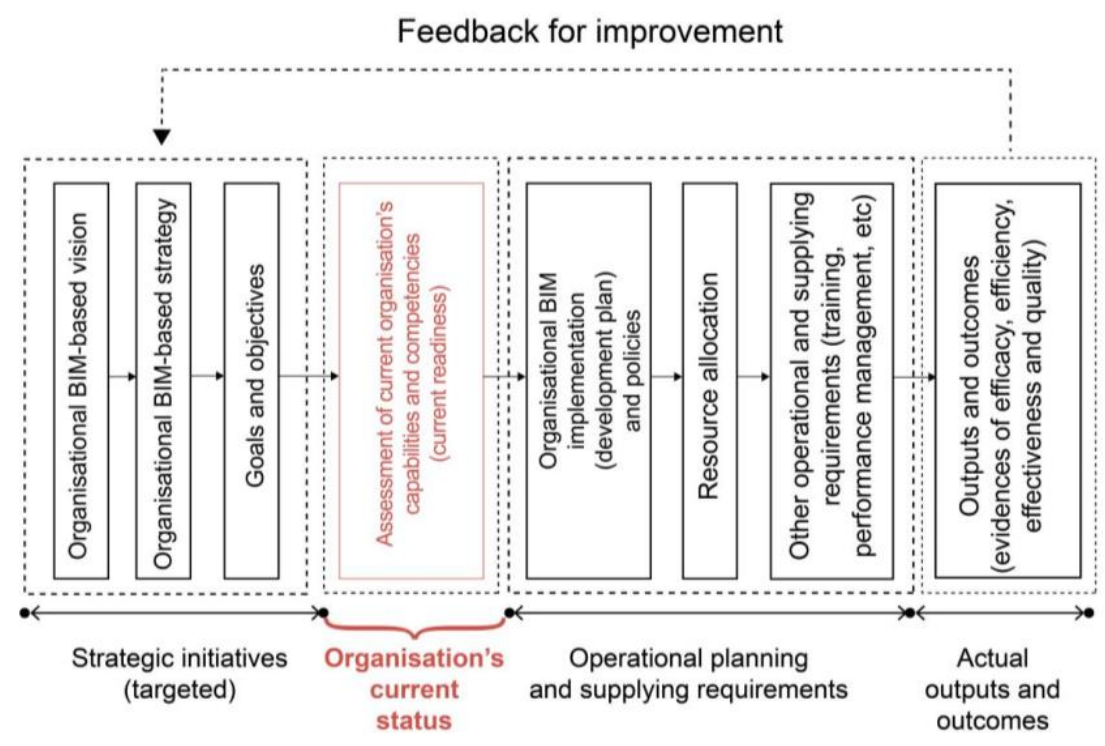

FIG. 7: The significance of readiness assessment in the conversion of strategic initiatives to operational planning 
From the practical point of view, BIM implementation involves more frequent inter- and intra-organizational collaboration and this collaboration can be overseen by establishing a coordinating structure such as a BIM division/committee. In small and medium enterprises (SMEs), this collaboration can be managed through individuals who possess BIM knowledge and expertise. The nominated BIM division can then be given autonomy to enable BIM leaders to play a leadership role in a number of BIM implementation aspects such as communicating to software vendors, educating potential adopters, leading BIM pilot projects and developing corporate policies. BIM leaders may also play a major role in nurturing the appropriate organizational culture which can assist the implementation of organizational changes as a result of BIM implementation.

Training and education is found as the highly cited BIM implementation enabler in the extant literature. The result of analysis further revels that training is a dependent variable which not only relies on a number of other variables such as resource availability and top management support, but also influence a number of other enablers such as performance management and cultural readiness throughout. For example, organizational culture aspects such as norms, values, and beliefs influences leverages BIM training programs which, in turn, impacts and redefines the culture components of the organizational structure. BIM training and education programs impact on what is interpreted by the trainees and what is valued by the organization as a whole, thereby reinforcing standards on values and behaviours. On the other hand, norms, values, and beliefs which collectively form organizational culture may influence the BIM learning environment. This is because trainees' learning outcomes and collaborative practices collectively represent the organizational culture. Taking into account a typical analysisdesign-develop-implement-evaluate (ADDIE) training model, training designers should consider organizational culture throughout all BIM training program steps. Incorporating a culture analysis within BIM training program planning will ultimately alleviate many of the bottlenecks that may arise during the implementation of a training and development program (cultural resistance and/or a clash of values between culture and training). In turn, training can be an effective tool in facilitating culture change within the organization. Through the lens of Structuration Theory, which goes beyond analyzing structures or agents/actors per se but rather an interplay of both (Stones, 2005), organizational culture and training development programs have an ongoing reciprocal relationship, rather than a snapshot with a one-time influence (Kissack \& Callahan, 2010). This therefore creates a need for a continuous culture analysis to inform all aspects of the BIM training program in question. In order for the training program to be an effective evaluation of trainees' readiness, a competency assessment is essential (Seyler et al., 1998). A number of training techniques and methods such as on-the-job training, simulations, case studies, role plays, and behavior modeling (Noe \& Tews, 2008) can be utilized while implementing BIM tools and concepts.

The other significant enabler which identified as a dependent variable in the MICMAC analysis is BIM performance management. BIM performance management can enable alignment by motivating staff and ensuring alignment in organizational strategy and process. Performance management improves decision-making by indicating how well and effective an organization has performed their BIM implementation efforts, the current status of BIM implementation (current maturity level) and where they need to be (higher maturity level) (Succar et al., 2012). To do this effectively, performance management would need to be relevant and accordingly linked with the overarching BIM vision, strategy and objectives. Additionally, measures must be agreed and shared by the BIM division and expertise especially when various groups and organization units (large-scale BIM implementation) are involved. BIM performance management can be inhibiting when it lacks relevance to the organizational BIM vision and objectives or moreover, when there is a deficiency in rigorous metrics and/or benchmarking mechanisms. The BIM performance management approach should take into account the dynamic nature of BIM implementation and dually be flexible enough to match a changing BIM strategic intent and vision over time. BIM Performance management must be interpreted as an approach to improve communication (to encourage teamwork), create accountability for BIM personnel and support priority setting. If properly aligned with organizational and broader stakeholders' BIM vision and objectives, performance management will act as a catalyst for change and allow employees to contribute to these objectives.

BIM process and performance management tools such as BIM capability and maturity assessment tools, benefits management tools and external benchmarking tools and metrics all require trained and committed individuals and/or teams. A lack of training and understanding of the potentially complex tasks involved can lead to decisions being made based on measurements unaligned with BIM strategy. An effective performance management needs to balance the requirements of the individual with the requirements of the organization and wider stakeholders in the overall BIM implementation process. Without this, employees would be provided performance reviews to 
improve certain measures that do not relate to a broader organizational vision, thereby instilling incorrect "improvements" and ultimately leading to tensions between functions (Muratoglu, 2008).

Organizations with functional tensions are often critiqued for their inability to respond to various external demands (Pagell, 2004; Van Hoek \& Mitchell, 2006). Yasin et al. (2005) proposed the use of a cross-functional reward system as a means of overcoming this. Additionally, BIM employees and practitioners must be motivated (beyond being trained) in order to successfully make desired changes. Employees' motivation and training protocols enhance any new management initiatives during the implementation of BIM.

Identifying the weakest areas and best practices for BIM implementation in a company is the first stage of process improvement which are obtained from the maturity assessment. They also require more than a simple assessment but an across the board analysis of their strengths and weaknesses. This reflects the significance of experience in applying the BIM capability and maturity assessment tools. There are different ways for conducting performance assessment tools including self-assessment (gathering information from internal members about the organization) or third-party assessment (extending the assessment by including external experts supporting the internal staff) and certified assessment (by outsourcing the process of assessment to a certified firm of practitioner). Thus, seeking support from both intra and inter organizational parties is essential and they all need to be backed by effective leadership and support from top management level. Furthermore, BIM benefit management entails an identification of specific benefits, distinguishing the benefits of not offering by BIM, identification of benefits that were previously 'unquantified' and 'unidentified', an identification of the means used to measure the BIM benefits and an identification of the individuals or teams responsible for achieving and measuring the benefits that BIM offers. As AEC organizations repeat their BIM processes and improve their BIM implementation efforts through continuous performance management, they are far more likely to make effective progress towards higher maturity and capability levels, as well as transition from collaborative efforts towards internal and external integration (Papadonikolaki \& Wamelink, 2017; Succar, 2009).

\section{CONCLUSION}

BIM implementation is considered a dynamic process requiring a procedural means of implementation. However, most of the extant studies within the BIM implementation domain analyze the key enablers involved independently. By neglecting to analyze the interrelationship between key enablers, the opportunity to gain a thorough and comprehensive understanding of the context in which BIM should be implemented is lost. The main aim of this study was to identify the key organizational BIM implementation enablers and to understand the mutual interrelationships between them. The results suggest that leadership and top management support are among the major enablers, which significantly reinforce the other enablers at play. The second is organizational structure, which should be treated as a guiding mechanism and involves aspects such as BIM strategy, the degree of centralization and formalization of organizational structure, and different structural forms such as matrix, functional and divisional.

Regardless of the type of BIM adoption initiation, the main strategic decisions commonly rely on the top management level for the adjustment of organizational structure, and adaptation and support of BIM implementation requirements. Effective leadership is likely to impact more on organizational culture, diminish the resistance to change and improve relational behaviors, norms and values, as well as information sharing amongst the varied organizational individuals and working groups involved. The BIM strategy and objectives should initially be aligned with the establishment of an overarching BIM vision. This will stimulate effective fulfillment and supply of operational enablers such as resource allocation, training and education, and a rigorous BIM performance management system with well-established metrics and benchmarks to encourage continuous measurement and improvement.

By employing a MICMAC analysis, this research offers an analysis of BIM implementation enablers in terms of their driving and dependence power. No enabler was found to be in the autonomous cluster on the MICMAC diagram (Figure 6). It was thus determined that all enablers are required for the implementation of BIM. Those enablers possessing a higher driving power in the BIM implementation process are to be given a greater priority as there are few other dependent enablers likely to be affected by them. The enablers with high driving power are of strategic orientation. Contrastingly, dependent enablers are more of operational and performance orientation. The results of this study can help in the strategic and operational decision making that design, engineering and 
construction firms rely on to gauge their readiness while transitioning from traditional to comprehensive BIMbased approaches.

These findings are particularly important for small-scale construction organizations such as architectural firms, subcontractors and suppliers who may not have the resources to implement all the BIM implementation enablers available. As has been discussed throughout, BIM implementation is a dynamic process where most of the key enablers are subject to continual adjustments. This flexibility thereby allows AEC organizations to continuously improve their implementation processes and efforts over time. For example, as BIM personnel interact with and conduct more experimentation, their experience and expectations are likely to increase and evolve beyond the initial time-frame required for the implementation stages. Subsequently, BIM leaders and managers can leverage their expectations to further refine the BIM vision. Similarly, as there are some unknown facts and variability in the initial phases of BIM adoption and implementation, there is a need for more frequent training and performance management initiatives to be undertaken. However, as BIM personnel achieve more experience, these can be subject to further alterations in due course. Therefore, the developed model herein should not be considered as a static model with one-off effects; rather, it should be treated as an iterative model with a set of dynamic enablers. This guides us to conduct more in depth investigations of the BIM adoption and implementation process.

There are some limitations to this study. The model developed was an ISM model with only eleven major enablers for implementing BIM. The number of enablers was limited to eleven in this case due to the inability of the ISM technique to accommodate too many variables. Hence, other enablers which are less critical to successful BIM implementation may have been omitted or incorporated as part of the existing constructs. Furthermore, the validation of the ISM model is based on the existing literature review and opinions of a small group of experts, which may be biased and not fully reflect industry practice. As a suggestion for future studies, the relationship among the identified BIM enablers can be further validated through adopting statistical analysis techniques such as Structural Equation Modeling (SEM).

\section{REFERENCES}

Abbasnejad, B., 2018. Building Information Modelling Adoption and Implementation in Construction Firms: A Multi-Stage Model. Ph.D. Thesis, Queensland University of Technology, Brisbane, Australia.

Abbasnejad, B., Nepal, M. and Drogemuller, R., 2016. Key enablers for effective management of BIM implementation in construction firms. In Proceedings of the CIB World Building Congress 2016: Volume I-Creating built environments of new opportunities (Vol. 1, pp. 622-633). TUT-Tampere University of Technology.

Ahn, Y.H., Kwak, Y.H. and Suk, S.J., 2016. Contractors' transformation strategies for adopting building information modeling. Journal of management in engineering, 32(1), p.05015005.

Ahuja, R., Jain, M., Sawhney, A. and Arif, M., 2016. Adoption of BIM by architectural firms in India: technologyorganization-environment perspective. Architectural Engineering and Design Management, 12(4), pp.311-330.

Ahuja, R., Sawhney, A. and Arif, M., 2017. Prioritizing BIM capabilities of an organization: an interpretive structural modeling analysis. Procedia engineering, 196, pp.2-10.

Al Ahbabi, M. and Alshawi, M., 2015. BIM for client organisations: a continuous improvement approach. Construction Innovation.

Almuntaser, T., Sanni-Anibire, M.O. and Hassanain, M.A., 2018. Adoption and implementation of BIM-case study of a Saudi Arabian AEC firm. International Journal of Managing Projects in Business.

Aranda-Mena, G., Crawford, J., Chevez, A. and Froese, T., 2009. Building information modelling demystified: does it make business sense to adopt BIM?. International Journal of managing projects in business.

Arayici, Y., Coates, P., Koskela, L., Kagioglou, M., Usher, C. and O'Reilly, K.J.S.S., 2011a. BIM adoption and implementation for architectural practices. Structural survey.

Arayici, Y., Coates, P., Koskela, L., Kagioglou, M., Usher, C. and O'Reilly, K., 2011b. Technology adoption in the BIM implementation for lean architectural practice. Automation in construction, 20(2), pp.189-195. 
Arayici, Y., Egbu, C.O. and Coates, S.P., 2012. Building information modelling (BIM) implementation and remote construction projects: issues, challenges, and critiques. Journal of Information Technology in Construction, 17, pp.75-92.

Attri, R., Grover, S., Dev, N. and Kumar, D., 2013a. An ISM approach for modelling the enablers in the implementation of total productive maintenance (TPM). International Journal of System Assurance Engineering and Management, 4(4), pp.313-326.

Attri, R., Dev, N. and Sharma, V., 2013b. Interpretive structural modelling (ISM) approach: an overview. Research Journal of Management Sciences, 2319, p.1171.

Ayinla, K.O. and Adamu, Z., 2018. Bridging the digital divide gap in BIM technology adoption. Engineering, Construction and Architectural Management.

Ayyaz, M., Ruikar, K. and Emmitt, S., 2012. Towards understanding BPR needs for BIM implementation. International Journal of 3-D Information Modeling (IJ3DIM), 1(4), pp.18-28.

Babatunde, S.O., Udeaja, C. and Adekunle, A.O., 2020. Barriers to BIM implementation and ways forward to improve its adoption in the Nigerian AEC firms. International Journal of Building Pathology and Adaptation.

Barki, H. and Pinsonneault, A., 2005. A model of organizational integration, implementation effort, and performance. Organization science, 16(2), pp.165-179.

Barlish, K. and Sullivan, K., 2012. How to measure the benefits of BIM-A case study approach. Automation in construction, 24, pp.149-159.

Becker, B.E. and Huselid, M.A., 2006. Strategic human resources management: where do we go from here?. Journal of management, 32(6), pp.898-925.

Belasen, A. and Frank, N., 2010. A peek through the lens of the competing values framework: What managers communicate and how. Atlantic Journal of communication, 18(5), pp.280-296.

Benner, M.J. and Tushman, M.L., 2003. Exploitation, exploration, and process management: The productivity dilemma revisited. Academy of management review, 28(2), pp.238-256.

Zahrizan, Z., Ali, N.M., Haron, A.T., Marshall-Ponting, A. and Abd, Z., 2013. Exploring the adoption of Building Information Modelling (BIM) in the Malaysian construction industry: A qualitative approach. International Journal of Research in Engineering and Technology, 2(8), pp.384-395.

Bosch-Sijtsema, P., Isaksson, A., Lennartsson, M. and Linderoth, H.C., 2017. Barriers and facilitators for BIM use among Swedish medium-sized contractors-"We wait until someone tells us to use it". Visualization in engineering, 5(1), p.3.

Boud, D., 2013. Enhancing learning through self-assessment. Routledge.

Bryde, D., Broquetas, M. and Volm, J.M., 2013. The project benefits of building information modelling (BIM). International journal of project management, 31(7), pp.971-980.

Cao, D., Li, H., Wang, G., Luo, X. and Tan, D., 2018. Relationship network structure and organizational competitiveness: Evidence from BIM implementation practices in the construction industry. Journal of management in engineering, 34(3), p.04018005.

Cerovsek, T., 2011. A review and outlook for a 'Building Information Model'(BIM): A multi-standpoint framework for technological development. Advanced engineering informatics, 25(2), pp.224-244.

Chan, D.W., Olawumi, T.O. and Ho, A.M., 2019a. Critical success factors for building information modelling (BIM) implementation in Hong Kong. Engineering, Construction and Architectural Management.

Chan, D.W., Olawumi, T.O. and Ho, A.M., 2019b. Perceived benefits of and barriers to Building Information Modelling (BIM) implementation in construction: The case of Hong Kong. Journal of Building Engineering, 25, p.100764. 
Chen, W.T., Merrett, H.C., Lu, S.T. and Mortis, L., 2019. Analysis of Key Failure Factors in Construction Partnering-A Case Study of Taiwan. Sustainability, 11(14), p.3994.

Chen, Y., Dib, H., Cox, R.F., Shaurette, M. and Vorvoreanu, M., 2016. Structural equation model of building information modeling maturity. Journal of Construction Engineering and Management, 142(9), p.04016032.

Christopher, M. and Gattorna, J., 2005. Supply chain cost management and value-based pricing. Industrial marketing management, 34(2), pp.115-121.

Chunduri, S., Kreider, R. and Messner, J.I., 2013. A case study implementation of the BIM planning procedures for facility owners. In AEI 2013: Building Solutions for Architectural Engineering (pp. 691-701).

Choi, J., Lee, J. and Cho, J., 2018. Suggestion of the core element technology to improve BIM data interoperability based on the energy performance analysis. International Journal of Grid and Distributed Computing, 11(4), pp.157-168.

Selçuk Çıdık, M., Boyd, D. and Thurairajah, N., 2017. Innovative capability of building information modeling in construction design. Journal of Construction Engineering and Management, 143(8), p.04017047.

Ciribini, A.L.C., Ventura, S.M. and Paneroni, M., 2016. Implementation of an interoperable process to optimise design and construction phases of a residential building: A BIM Pilot Project. Automation in Construction, 71, pp.62-73.

Coates, P., Arayici, Y., Koskela, K., Kagioglou, M., Usher, C. and O'Reilly, K., 2010. The key performance indicators of the BIM implementation process.

Colin, J., Estampe, D., Pfohl, H.C., Gallus, P. and Thomas, D., 2011. Interpretive structural modeling of supply chain risks. International Journal of physical distribution \& logistics management.

Dakhil, A.J., Underwood, J. and Alshawi, M., 2019. Critical success competencies for the BIM implementation process: UK construction clients. Journal of Information Technology in Construction (ITcon), 24, pp.8094.

Dossick, C.S. and Neff, G., 2010. Organizational divisions in BIM-enabled commercial construction. Journal of construction engineering and management, 136(4), pp.459-467.

Dowsett, R.M. and Harty, C.F., 2019. Assessing the implementation of BIM-an information systems approach. Construction management and economics, 37(10), pp.551-566.

Du, J., Liu, R. and Issa, R.R., 2014. BIM cloud score: benchmarking BIM performance. Journal of Construction Engineering and Management, 140(11), p.04014054.

Eadie, R., Browne, M., Odeyinka, H., McKeown, C. and McNiff, S., 2013. BIM implementation throughout the UK construction project lifecycle: An analysis. Automation in construction, 36, pp.145-151.

Elmualim, A. and Gilder, J., 2014. BIM: innovation in design management, influence and challenges of implementation. Architectural Engineering and design management, 10(3-4), pp.183-199.

Enegbuma, W.I., Aliagha, U.G. and Ali, K.N., 2014. Preliminary building information modelling adoption model in Malaysia. Construction Innovation, 14(4), p.408.

Fidler, L.A. and Johnson, J.D., 1984. Communication and innovation implementation. Academy of management review, 9(4), pp.704-711.

Fredrickson, J.W., 1986. The strategic decision process and organizational structure. Academy of management review, 11(2), pp.280-297.

Gann, D.M. and Salter, A.J., 2000. Innovation in project-based, service-enhanced firms: the construction of complex products and systems. Research policy, 29(7-8), pp.955-972.

Garvin, D.A., 1998. The processes of organization and management. Sloan management review, 39(4), pp.33-51. 
Ghaffarianhoseini, A., Doan, D.T., Zhang, T., Ghaffarianhoseini, A., Naismith, N. and Tookey, J., 2016. A BIM readiness \& implementation strategy for SME construction companies in the UK. In Proceedings of the $33 r d$ CIB W78 Conference.

Giel, B. and Issa, R.R., 2013. Quality and Maturity of BIM Implementation in the AECO Industry. In Applied Mechanics and Materials (Vol. 438, pp. 1621-1627). Trans Tech Publications Ltd.

Giel, B. and Issa, R.R., 2016. Framework for evaluating the BIM competencies of facility owners. Journal of management in engineering, 32(1), p.04015024.

Gledson, B.J., 2016. Hybrid project delivery processes observed in constructor BIM innovation adoption. Construction innovation.

Gregory, K.L., 1983. Native-view paradigms: Multiple cultures and culture conflicts in organizations. Administrative science quarterly, pp.359-376.

Grilo, A. and Jardim-Goncalves, R., 2010. Value proposition on interoperability of BIM and collaborative working environments. Automation in construction, 19(5), pp.522-530.

Gu, N. and London, K., 2010. Understanding and facilitating BIM adoption in the AEC industry. Automation in construction, 19(8), pp.988-999.

Hage, J.T., 1999. Organizational innovation and organizational change. Annual review of sociology, 25(1), pp.597622.

Henderson, J.R. and Ruikar, K., 2010. Technology implementation strategies for construction organisations. Engineering, Construction and Architectural Management.

Hess, T.M., Emery, L. and Neupert, S.D., 2012. Longitudinal relationships between resources, motivation, and functioning. Journals of Gerontology Series B: Psychological Sciences and Social Sciences, 67(3), pp.299-308.

Homayouni, H., Neff, G. and Dossick, C.S., 2010. Theoretical categories of successful collaboration and BIM implementation within the AEC industry. In Construction Research Congress 2010: Innovation for Reshaping Construction Practice (pp. 778-788).

Hong, Y., Hammad, A.W., Sepasgozar, S. and Akbarnezhad, A., 2019. BIM adoption model for small and medium construction organisations in Australia. Engineering, Construction and Architectural Management.

Reza Hosseini, M., Pärn, E.A., Edwards, D.J., Papadonikolaki, E. and Oraee, M., 2018. Roadmap to mature BIM use in Australian SMEs: Competitive dynamics perspective. Journal of management in engineering, 34(5), p.05018008.

Howard, R., Restrepo, L. and Chang, C.Y., 2017. Addressing individual perceptions: An application of the unified theory of acceptance and use of technology to building information modelling. International Journal of Project Management, 35(2), pp.107-120.

Husain, A.H., Razali, M.N. and Eni, S., 2018. Stakeholders' expectations on building information modelling (BIM) concept in Malaysia. Property Management.

Jensen, P.A. and Jóhannesson, E.I., 2013. Building information modelling in Denmark and Iceland. Engineering, Construction and Architectural Management.

Jin, R., Hancock, C., Tang, L., Chen, C., Wanatowski, D. and Yang, L., 2017. Empirical study of BIM implementation-based perceptions among Chinese practitioners. Journal of management in engineering, 33(5), p.04017025.

Juan, Y.K., Lai, W.Y. and Shih, S.G., 2017. Building information modeling acceptance and readiness assessment in Taiwanese architectural firms. Journal of Civil Engineering and Management, 23(3), pp.356-367.

Jung, Y. and Joo, M., 2011. Building information modelling (BIM) framework for practical implementation. Automation in construction, 20(2), pp.126-133. 
Kam, C., Senaratna, D., McKinney, B., Xiao, Y. and Song, M., 2013. The VDC scorecard: Formulation and validation. Center for Integrated Facility Engineering: Stanford University.

Kay, H., 2004. Matching leadership style to team maturity. In ASQ World Conference on Quality and Improvement Proceedings (Vol. 58, p. 97). American Society for Quality.

Keskin, B., Ozorhon, B. and Koseoglu, O., 2019. BIM implementation in mega projects: challenges and enablers in the Istanbul Grand Airport (IGA) project. In Advances in Informatics and Computing in Civil and Construction Engineering (pp. 881-888). Springer, Cham.

Kettinger, W.J. and Grover, V., 1995. Toward a theory of business process change management. Journal of Management Information Systems, 12(1), pp.9-30.

Khosrowshahi, F. and Arayici, Y., 2012. Roadmap for implementation of BIM in the UK construction industry. Engineering, Construction and Architectural Management.

Kissack, H.C. and Callahan, J.L., 2010. The reciprocal influence of organizational culture and training and development programs. Journal of European Industrial Training.

Klein, K.J. and Knight, A.P., 2005. Innovation implementation: Overcoming the challenge. Current directions in psychological science, 14(5), pp.243-246.

Kokkonen, A. and Alin, P., 2016. Practitioners deconstructing and reconstructing practices when responding to the implementation of BIM. Construction management and economics, 34(7-8), pp.578-591.

Koseoglu, O., Keskin, B. and Ozorhon, B., 2019. Challenges and enablers in BIM-enabled digital transformation in mega projects: The Istanbul new airport project case study. Buildings, 9(5), p.115.

Kotterman, J., 2006. Leadership versus management: what's the difference?. The Journal for Quality and Participation, 29(2), p.13.

Krackhardt, D. and Kilduff, M., 1990. Friendship patterns and culture: The control of organizational diversity. American anthropologist, 92(1), pp.142-154.

Ku, K. and Taiebat, M., 2011. BIM experiences and expectations: the constructors' perspective. International Journal of Construction Education and Research, 7(3), pp.175-197.

Kuyvenhoven, R. and Buss, W.C., 2011. A normative view of the role of middle management in the implementation of strategic change. Journal of Management and Marketing Research, 8, p.1.

Lee, S., Yu, J. and Jeong, D., 2015. BIM acceptance model in construction organizations. Journal of management in engineering, 31(3), p.04014048.

Li, D., Li, X., Feng, H., Wang, Y. and Fan, S., 2019. ISM-based relationship among critical factors that affect the choice of prefabricated concrete buildings in China. International Journal of Construction Management, pp.1-16.

Liang, C., Lu, W., Rowlinson, S. and Zhang, X., 2016. Development of a multifunctional BIM maturity model. Journal of construction engineering and management, 142(11), p.06016003.

Liao, L. and Teo, E.A.L., 2019. Managing critical drivers for building information modelling implementation in the Singapore construction industry: an organizational change perspective. International Journal of Construction Management, 19(3), pp.240-256.

Liao, X., Lee, C.Y. and Chong, H.Y., 2019. Contractual practices between the consultant and employer in Chinese BIM-enabled construction projects. Engineering, Construction and Architectural Management.

Liao, L. and Ai Lin Teo, E., 2018. Organizational change perspective on people management in BIM implementation in building projects. Journal of management in engineering, 34(3), p.04018008.

Lindblad, H., 2019. Black boxing BIM: the public client's strategy in BIM implementation. Construction management and economics, 37(1), pp.1-12. 
Linderoth, H.C., 2010. Understanding adoption and use of BIM as the creation of actor networks. Automation in construction, 19(1), pp.66-72.

Lines, B.C. and Reddy Vardireddy, P.K., 2017. Drivers of organizational change within the AEC industry: Linking change management practices with successful change adoption. Journal of management in engineering, 33(6), p.04017031.

Ling, F.Y.Y., 2003. Managing the implementation of construction innovations. Construction management and economics, 21(6), pp.635-649.

Love, P.E., Matthews, J., Simpson, I., Hill, A. and Olatunji, O.A., 2014. A benefits realization management building information modeling framework for asset owners. Automation in construction, 37, pp.1-10.

Lu, Y., Wu, Z., Chang, R. and Li, Y., 2017. Building Information Modeling (BIM) for green buildings: A critical review and future directions. Automation in Construction, 83, pp.134-148.

Lysaght, R.M. and Altschuld, J.W., 2000. Beyond initial certification: the assessment and maintenance of competency in professions. Evaluation and Program Planning, 23(1), pp.95-104.

Ma, G., Jia, J., Ding, J., Shang, S. and Jiang, S., 2019. Interpretive structural model based factor analysis of BIM adoption in Chinese construction organizations. Sustainability, 11(7), p.1982.

Mahamadu, A.M., Mahdjoubi, L. and Booth, C.A., 2017. Critical BIM qualification criteria for construction prequalification and selection. Architectural Engineering and Design Management, 13(5), pp.326-343.

Mason, J. and Knott, M., 2016. Is the lack of a common BIM vision between clients and contractors a cause for concern?. Creating built environments of new opportunities, 1, p.673.

Mayo, G., Giel, B. and Issa, R.R., 2012. BIM use and requirements among building owners. In Computing in civil engineering (2012) (pp. 349-356).

Mehran, D., 2016. Exploring the Adoption of BIM in the UAE Construction Industry for AEC Firms. Procedia Engineering, 145, pp.1110-1118.

Merschbrock, C., Hosseini, M.R., Martek, I., Arashpour, M. and Mignone, G., 2018. Collaborative role of sociotechnical components in BIM-based construction networks in two hospitals. Journal of Management in Engineering, 34(4), p.05018006.

Miettinen, R. and Paavola, S., 2014. Beyond the BIM utopia: Approaches to the development and implementation of building information modeling. Automation in construction, 43, pp.84-91.

Mishchenko, E.S., Monastyrev, P.V. and Evdokimtsev, O.V., 2018, September. Improving the Quality of Training in Building Information Modeling. In International Conference on Interactive Collaborative Learning (pp. 453-459). Springer, Cham.

Mohamed, M.R., Mohammad, M.F., Mahbub, R., Ramli, M.A., Gunasagaran, S. and Halim, S.M.A., 2019. Business Strategy of Small and Medium-Sized Enterprise Construction Companies in Adopting Industrialised Building System in Malaysia. INTERNATIONAL JOURNAL OF ACADEMIC RESEARCH IN BUSINESS AND SOCIAL SCIENCES, 9(9).

Mom, M., Tsai, M.H. and Hsieh, S.H., 2014. Developing critical success factors for the assessment of BIM technology adoption: Part II. Analysis and results. Journal of the Chinese Institute of Engineers, 37(7), pp.859-868.

Muratoglu, K., 2008. Performance measurement of supply chain via balanced scorecard: the case of a brewing group. The Business Review, 10(1), pp.330-7.

Murphy, M.E., 2014. Implementing innovation: a stakeholder competency-based approach for BIM. Construction innovation, 14(4), p.433.

Musa, S., 2019. A framework of intra-organisational knowledge sharing practices in implementing BIM within the Malaysian construction industry (Doctoral dissertation, University of Salford). 
Nikas, A., Poulymenakou, A. and Kriaris, P., 2007. Investigating antecedents and drivers affecting the adoption of collaboration technologies in the construction industry. Automation in construction, 16(5), pp.632-641.

Ngowtanasuwan, G. and Hadikusumo, B.H., 2017. System dynamics modelling for BIM adoption in Thai architectural and engineering design industry. Construction Innovation.

Noe, R.A. and Tews, M.J., 2008. Strategic training and development: Raymond A. Noe and Michael J. Tews. In The Routledge companion to strategic human resource management (pp. 276-298). Routledge.

Olatunji, O., 2011. Modelling organizations' structural adjustment to BIM adoption: a pilot study on estimating organisations. Journal of information technology in construction, 16, pp.653-668.

Oliveira, T. and Martins, M.F., 2010, September. Information technology adoption models at firm level: review of literature. In The European Conference on Information Systems Management (p. 312). Academic Conferences International Limited.

OLUGBOYEGA, O. and WINDAPO, A., 2019. A COMPREHENSIVE BIM IMPLEMENTATION MODEL FOR DEVELOPING COUNTRIES. Journal of Construction Project Management and Innovation, 9(2), pp.83-104.

Ozorhon, B. and Karahan, U., 2017. Critical success factors of building information modeling implementation. Journal of Management in Engineering, 33(3), p.04016054.

Pagell, M., 2004. Understanding the factors that enable and inhibit the integration of operations, purchasing and logistics. Journal of operations management, 22(5), pp.459-487.

Papadonikolaki, E., Vrijhoef, R. and Wamelink, H., 2016. The interdependences of BIM and supply chain partnering: empirical explorations. Architectural Engineering and Design Management, 12(6), pp.476494.

Papadonikolaki, E., Verbraeck, A. and Wamelink, H., 2017. Formal and informal relations within BIM-enabled supply chain partnerships. Construction management and economics, 35(8-9), pp.531-552.

Papadonikolaki, E., 2018. Loosely coupled systems of innovation: Aligning BIM adoption with implementation in Dutch construction. Journal of management in engineering, 34(6), p.05018009.

Park, E., Kwon, S.J. and Han, J., 2019. Antecedents of the adoption of building information modeling technology in Korea. Engineering, Construction and Architectural Management.

Peansupap, V. and Walker, D.H., 2005. Factors enabling information and communication technology diffusion and actual implementation in construction organisations. ITcon, 10(14), pp.193-218.

Peters Thomas, J. and Waterman Robert, H., 1982. In search of excellence: lessons from America's best-run companies. NY: Harper \& Row, Publishers Inc.

Poirier, E., Staub-French, S. and Forgues, D., 2015. Embedded contexts of innovation. Construction innovation.

Popov, V., Juocevicius, V., Migilinskas, D., Ustinovichius, L. and Mikalauskas, S., 2010. The use of a virtual building design and construction model for developing an effective project concept in 5D environment. Automation in construction, 19(3), pp.357-367.

Ragu-Nathan, B.S., Apigian, C.H., Ragu-Nathan, T.S. and Tu, Q., 2004. A path analytic study of the effect of top management support for information systems performance. Omega, 32(6), pp.459-471.

Rahimian, F.P., Ibrahim, R. and Murphy, M.E., 2014. Implementing innovation: a stakeholder competency-based approach for BIM. Construction Innovation.

Raj, T., Shankar, R. and Suhaib, M., 2008. An ISM approach for modelling the enablers of flexible manufacturing system: the case for India. International Journal of Production Research, 46(24), pp.6883-6912.

Rezgui, Y., Beach, T. and Rana, O., 2013. A governance approach for BIM management across lifecycle and supply chains using mixed-modes of information delivery. Journal of civil engineering and management, 19(2), pp.239-258. 
Rogers, E.M., 2003. Diffusion of Innovations Fifth edition Free Press.

Rogers, J., Chong, H.Y. and Preece, C., 2015. Adoption of building information modelling technology (BIM). Engineering, Construction and Architectural Management.

Sackey, E. and Akotia, J., 2017. Spanning the multilevel boundaries of construction organisations. Construction Innovation.

Sackey, E., Tuuli, M. and Dainty, A., 2015. Sociotechnical systems approach to BIM implementation in a multidisciplinary construction context. Journal of management in engineering, 31(1), p.A4014005.

Saka, A.B. and Chan, D.W., 2020. Profound barriers to building information modelling (BIM) adoption in construction small and medium-sized enterprises (SMEs). Construction Innovation.

Samuelson, O. and Björk, B.C., 2013. Adoption processes for EDM, EDI and BIM technologies in the construction industry. Journal of Civil Engineering and Management, 19(sup1), pp.S172-S187.

Sarhan, J.G., Xia, B., Fawzia, S., Karim, A., Olanipekun, A.O. and Coffey, V., 2019. Framework for the implementation of lean construction strategies using the interpretive structural modelling (ISM) technique. Engineering, Construction and Architectural Management.

Schein, E.H., 1985. Defining organizational culture. Classics of organization theory, 3(1), pp.490-502.

Sebastian, R. and van Berlo, L., 2010. Tool for benchmarking BIM performance of design, engineering and construction firms in the Netherlands. Architectural Engineering and Design Management, 6(4), pp.254263.

Sepasgozar, S.M., Davis, S.R., Li, H. and Luo, X., 2018. Modeling the implementation process for new construction technologies: Thematic analysis based on Australian and US practices. Journal of Management in Engineering, 34(3), p.05018005.

Seyler, D.L., Holton III, E.F., Bates, R.A., Burnett, M.F. and Carvalho, M.A., 1998. Factors affecting motivation to transfer training. International Journal of Training and development, 2(1), pp.16-16.

Shang, Z. and Shen, Z., 2014. Critical success factors (CSFs) of BIM implementation for collaboration based on system analysis. In Computing in Civil and Building Engineering (2014) (pp. 1441-1448).

Shin, J. and Choi, J., 2016. Development of Key Performance Indicators of BIM Performance Measurement in Design Phase. International Information Institute (Tokyo). Information, 19(10A), p.4469.

Siebelink, S., Voordijk, J.T. and Adriaanse, A., 2018. Developing and testing a tool to evaluate BIM maturity: Sectoral analysis in the Dutch construction industry. Journal of construction engineering and management, 144(8), p.05018007.

Siebelink, S., Voordijk, H., Endedijk, M. and Adriaanse, A., 2020. Understanding barriers to BIM implementation: Their impact across organizational levels in relation to BIM maturity. Frontiers of Engineering Management, pp.1-22.

Singh, M.D. and Kant, R., 2008. Knowledge management barriers: An interpretive structural modeling approach. International Journal of Management Science and Engineering Management, 3(2), pp.141-150.

Slaughter, E.S., 2000. Implementation of construction innovations. Building research \& information, 28(1), pp.217.

Slaughter, E.S., 1998. Models of construction innovation. Journal of Construction Engineering and management, 124(3), pp.226-231.

Son, H., Lee, S. and Kim, C., 2015. What drives the adoption of building information modeling in design organizations? An empirical investigation of the antecedents affecting architects' behavioral intentions. Automation in construction, 49, pp.92-99.

Stones, R., 2005. Structuration theory. Macmillan International Higher Education. 
Succar, B., 2009. Building information modelling framework: A research and delivery foundation for industry stakeholders. Automation in construction, 18(3), pp.357-375.

Succar, B., 2010, May. The five components of BIM performance measurement. In CIB World Congress (p. 14).

Succar, B. and Kassem, M., 2015. Macro-BIM adoption: Conceptual structures. Automation in construction, 57, pp.64-79.

Succar, B. and Poirier, E., 2020. Lifecycle information transformation and exchange for delivering and managing digital and physical assets. Automation in Construction, 112, p.103090.

Succar, B., Sher, W. and Williams, A., 2012. Measuring BIM performance: Five metrics. Architectural Engineering and Design Management, 8(2), pp.120-142.

Succar, B., Sher, W. and Williams, A., 2013. An integrated approach to BIM competency assessment, acquisition and application. Automation in construction, 35, pp.174-189.

Thong, J.Y., Yap, C.S. and Raman, K.S., 1996. Top management support, external expertise and information systems implementation in small businesses. Information systems research, 7(2), pp.248-267.

Thong, J.Y., Yap, C.S. and Raman, K.S., 1997. Environments for information systems implementation in small businesses. Journal of organizational computing and electronic commerce, 7(4), pp.253-278.

Tsai, M.H., Mom, M. and Hsieh, S.H., 2014. Developing critical success factors for the assessment of BIM technology adoption: part I. Methodology and survey. Journal of the Chinese Institute of Engineers, 37(7), pp.845-858.

Van Hoek, R.I. and Mitchell, A.J., 2006. The challenge of internal misalignment. International Journal of Logistics, 9(3), pp.269-281.

Vass, S. and Gustavsson, T.K., 2017. Challenges when implementing BIM for industry change. Construction management and economics, 35(10), pp.597-610.

Verma, A., Seth, N. and Singhal, N., 2018. Application of interpretive structural modelling to establish interrelationships among the enablers of supply chain competitiveness. Materials Today: Proceedings, 5(2), pp.4818-4823.

Vidalakis, C., Abanda, F.H. and Oti, A.H., 2020. BIM adoption and implementation: focusing on SMEs. Construction Innovation.

Volk, R., Stengel, J. and Schultmann, F., 2014. Building Information Modeling (BIM) for existing buildingsLiterature review and future needs. Automation in construction, 38, pp.109-127.

Wang, G. and Song, J., 2017. The relation of perceived benefits and organizational supports to user satisfaction with building information model (BIM). Computers in Human Behavior, 68, pp.493-500.

Ward, J. and Daniel, E., 2006. Benefits management: Delivering value from IS \& IT investments (Vol. 30). Chichester: John Wiley \& Sons.

Warfield, J.N., 1976. Societal systems. Planning, Policy and Complexity.

Watson, G.H., 1993. Strategic benchmarking: How to rate your company's performance against the world's best. Wiley.

Wenger, E., McDermott, R.A. and Snyder, W., 2002. Cultivating communities of practice: A guide to managing knowledge. Harvard Business Press.

Wilson, I., 1992. Realizing the power of strategic vision. Long range planning, 25(5), pp.18-28.

Won, J., Lee, G., Dossick, C. and Messner, J., 2013. Where to focus for successful adoption of building information modeling within organization. Journal of construction engineering and management, 139(11), p.04013014. 
Wu, W. and Issa, R.R., 2014. Key issues in workforce planning and adaptation strategies for BIM implementation in construction industry. In Construction Research Congress 2014: Construction in a Global Network (pp. 847-856).

Wu, C., Xu, B., Mao, C. and Li, X., 2017. Overview of BIM maturity measurement tools. Journal of Information Technology in Construction (ITcon), 22(3), pp.34-62.

Wu, W., Mayo, G., McCuen, T.L., Issa, R.R. and Smith, D.K., 2018a. Building information modeling body of knowledge. I: Background, framework, and initial development. Journal of Construction Engineering and Management, 144(8), p.04018065.

Wu, W., Mayo, G., McCuen, T.L., Issa, R.R. and Smith, D.K., 2018b. Building information modeling body of knowledge. II: Consensus building and use cases. Journal of Construction Engineering and Management, 144(8), p.04018066.

Yadav, D.K. and Barve, A., 2015. Analysis of critical success factors of humanitarian supply chain: An application of Interpretive Structural Modeling. International journal of disaster risk reduction, 12, pp.213-225.

Yasin, M.M., Bayes, P.E. and Czuchry, A.J., 2005. The changing role of accounting in supporting the quality and customer goals of organizations: an open system perspective. International Journal of Management, 22(3), p.323.

Zhou, Y., Ding, L., Rao, Y., Luo, H., Medjdoub, B. and Zhong, H., 2017. Formulating project-level building information modeling evaluation framework from the perspectives of organizations: a review. Automation in construction, 81 , pp.44-55. 